\title{
From tendon injury to collagen-based tendon regeneration: overview and recent advances
}

\author{
Clément Rieu ${ }^{\mathrm{a}, \dagger}$, Lise Picaut ${ }^{\mathrm{a}, \mathrm{b}, \dagger}$, Gervaise Mosser ${ }^{\mathrm{a}}$ and Léa Trichet ${ }^{\mathrm{a},{ }^{*}}$
}

${ }^{a}$ Sorbonne Universités, UPMC Université Paris 06, CNRS, Collège de France, Laboratoire de Chimie de la Matière Condensée de Paris, F-75005, France

${ }^{b}$ Sorbonne Universités, UPMC Université Paris 06, CNRS UMR 7588, Institut des NanoSciences de Paris, F-75005, Paris, France

${ }^{\dagger}$ These authors contributed equally to this work.

\begin{abstract}
Tendon injury is a clinical, societal and economical issue. Moreover, tendon repair represents an important clinical challenge, partly due to the mechanical constraints that occur at the junctions with muscle and bone. Several strategies have been developed for tendon repair. In this review, we first assess the importance of tendon injuries from different sites and their causes. After a short overview of tendon three-dimensional organization, the complexity of the perfect repair quest is presented ranging from current clinical procedures to new engineering scaffolds. We then sum up tendon engineering requirements and focus on new collagen-based scaffolds, which raise promising prospects to mimic and repair tendon. In particular, we survey quantitatively a large panel of techniques to produce these scaffolds, detailing their principle and recent improvements.
\end{abstract}

Keywords: tendon, injury, repair, biomaterial, graft, collagen, scaffold

\footnotetext{
*Address correspondence to this author at the Laboratoire de Chimie de la Matière Condensée de Paris, UPMC, Tour 43-44, Et. 4, 4 place Jussieu, 75252 Paris Cedex 05, France; Tel/Fax: +33-1-44276553,+33-1-44278102; E-mail: lea.trichet@upmc.f
} 


\section{INTRODUCTION: CLINICAL CHALLENGES}

Tendons can present acute or chronic injuries caused by extrinsic or intrinsic factors, either alone or in combination (Figure 1) [1]. Tendinopathies refer to the various chronic conditions that can affect tendons. They can remain silent over a large period of time, cause chronic pain and, potentially, lead to tendon tears and ruptures. These can also occur following lacerations by a sharp object or a tensile overload, in which case, it is now believed that an underlying tendinopathy is also involved [2], [3]. The term tendinitis, previously used, referred to tendon micro-tears associated with acute injuries due to an overload, causing inflammation, while tendinosis accounted for chronic wound following tendon overuse. The term tendinopathies is now preferred because there is no assumption about the underlying pathology, especially since the role of inflammation is still under debate [4], [5]. They are associated with a change in remodeling activity of tendon matrix.

External causes of tendinopathies include occupational, sporting activities, and prescription drugs [6]. Intrinsic factors include age and biomechanical imbalance [1]. The etiology of tendinopathies often appears to be multifactorial [2], [3], [7].

A UK study, performed in an acute Orthopedic Unit treating a well-defined catchment population of about 535,000 and prospectively recording the demographic details over 5 years, provided results about the incidence of musculoskeletal tissue trauma [8]. One of the findings is that about two thirds of tendon injuries relate to the hand. Among them, forearm/hand extensor tendon injuries occur with an annual incidence of 17.87/100,000, and mallet finger involving extensor tendon affecting mobility of the last phalanx, at a rate of 9.89/100,000 (Figure 1). A 10-year population-based study led in the US, examining hand or wrist open wounds secondary to acute trauma and involving tendons, found an incidence rate of 33.2 tendon injuries per 100,000 person-years, with work-related injuries accounting for $24.9 \%$ of total [9].

Achilles tendon rupture occurs at an annual rate of 11.33/100,000 according to Clayton et al. (2008) [8] and has already been reported with rates ranging from 5.5 to 18/100,000 (Figure 1) [10]. Most acute ruptures concern people in their thirties and forties during sports activities. Achilles tendinopathy has a 5.9\% lifetime cumulative incidence among sedentary people as compared to 50\% among endurance athletes [11]. Tennis elbow, also known as lateral elbow tendinopathy, is secondary to excessive use of wrist extensors and forearm supinators. It is usually reported to affect 1 to $3 \%$ of the population each year, however, a descriptive epidemiology study shows a decrease in the incidence with a rate of 3.4 per 1,000 [12].
The injury incidence in tennis players has been reported in proportions between 9 and 35\% [13]. The rotator cuff, which is composed of four muscle-tendon units that originate on the scapula and cover the top of the humeral head, can also often be subject to tendinopathy. In a prospective study, the sex and age-standardized incidence of shoulder pain was evaluated to be 9.5/1,000 among the patients presenting to general practice, with a proportion of $85 \%$ related to rotator cuff tendinopathy [14]. The incidence of rotator cuff tears was reported to be $3.73 / 100,000[8]$.

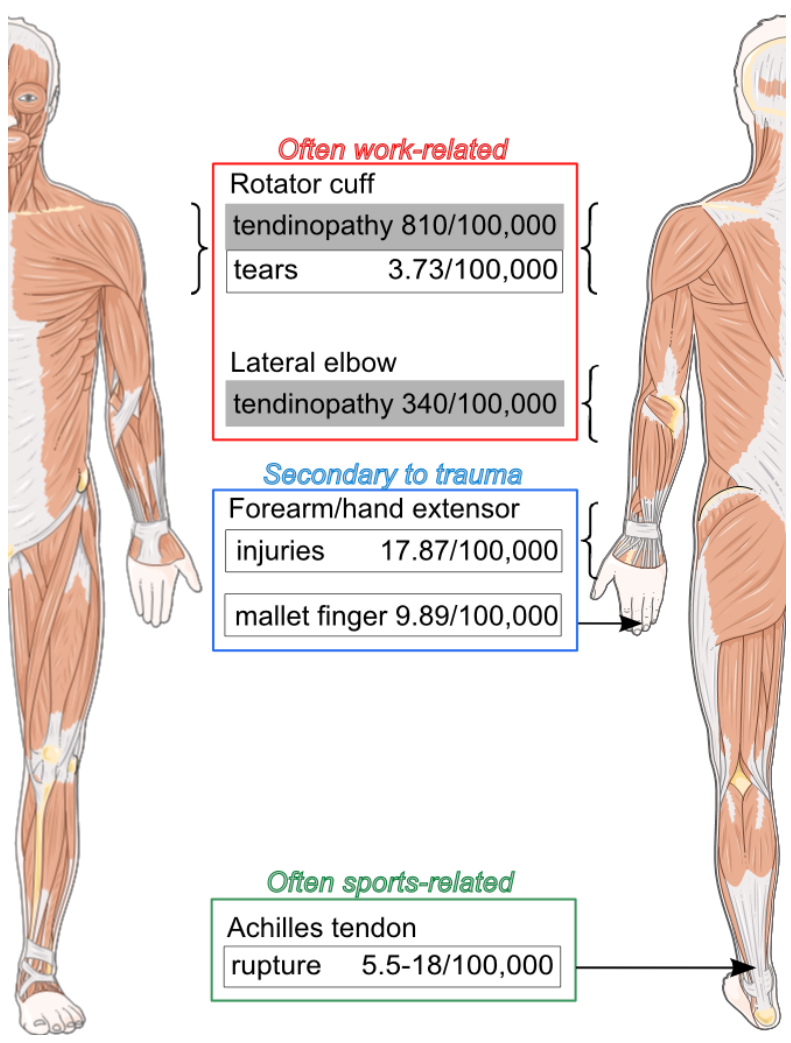

Figure 1: Location, annual incidence and main cause of most frequent tendon injuries. Data are referenced in the text. Sources: [8], [10]-[12]. Body image, courteously provided by Servier Medical Art under license https://creativecommons.org/licenses/by/3.0/fr/, , was modified for clarity purpose.

Work-related musculo-skeletal disorders concerning tendons are evident in occupations involving prolonged periods of repetitive, static work [14]. The prevalence of work related upper limb musculoskeletal disorders in UK was estimated to be 730 per 100,000 people in year 2014/2015 [15]. There is an average of 17.7 working days lost for each case. According to the 2005 data collection of Eurostat figures on recognized occupational diseases (EODS) of 12 member states, the most common musculo- 
skeletal occupational disease was lateral elbow tendinopathy (14,155 cases) [14]. In the United States, shoulder injury has been found to be the second most common cause after back pain for time away from work in manual laborers [16]. $41.5 \%$ of occupational shoulder injuries required more than 31 days away from work in 2007. In Sweden in 1995 among the 9,398 reported workrelated soft tissue diseases 217 cases involved rotator cuff and 538 lateral elbow [17]. Some estimates of the cost of work-related upper limb and neck musculo-skeletal disorders are between 0.5 and $2 \%$ of gross national product [17].

Due to poor vascularization and low cellularity of the tissue, there is limited spontaneous regeneration of tendon. Treatments can be conservative or surgical, or a combination of both with post-intervention rehabilitation programs [2], [5], [10], [16]. Currently there is a high rate of re-injury. In the case of small and large rotator cuff tears, surgical repairs of ruptured tendons have re-tear rates of up to 35 and $94 \%$, respectively [18]. Clinicians assess an unsatisfactory clinical outcome after suture for $25 \%$ of patients with hand tendon lacerations, and $7.7 \%$ of these repairs re-rupture [19].

\section{TENDON STRUCTURE AND REMAINING QUESTIONS}

Tendons and ligaments belong to connective tissues that present a cellular part and an extra-cellular matrix (ECM). Cells, out of which tenocytes are predominant, are found immersed into the ECM. They synthesize the biocomponents and thus play a major role in the setting and renewing of the ECM. This last one is responsible for the structural and mechanical properties, and maintains the integrity of the tissue [20]. ECM is composed of many different biochemical components such as collagens, noncollagen proteins, and proteoglycans [21][22].

Collagens are widespread and play major roles in organisms. They constitute a family of 28 members [23], all being formed by three polypeptides chains. Each chain has repeating amino-acid triplet units -(Glycine$\mathrm{XY})_{\mathrm{n}^{-}}$, that extend variably depending on the family member, and with $\mathrm{X}$ and $\mathrm{Y}$ positions frequently occupied by proline and hydroxyproline. The presence of those (Glycine-XY $)_{\mathrm{n}^{-}}$, repeats leads to polyproline-II segments that supercoil into a right-handed helix. Each member of the family has different functions and members can be, or not, co-localized, depending on the connective tissue considered. In tendon, collagens reach a concentration of $30-31.6 \%$ of the wet weight [24], and $60-85 \%$ of the dry weight of the tissue [22]. In the collagen family, collagen I is the major structuring bio-component of the tendon, where it is found in its fibril form and arranged into a hierarchical manner as we will see later.

Among the other components found in the ECM, some regulate collagen fibril diameters and/or fibrils interdistance and mechanical properties. For instance, polysaccharides form bridges between fibrils maintaining the equidistance between them and contribute in holding the three-dimensional network. Those bridges are formed by small carbohydrate chains of about $15 \mathrm{kDa}$ [25]. In vitro, it was also reported that, in the synthesis of collagen scaffolds, the addition of decorin increased their mechanical properties.

Tendon structure has been studied for the past decades and by various techniques and under various states. Despite the information acquired, the exact organization of tendon in living tissues remains unclear. The fact that it may be adapted to each location within the body and depend on species, does not help in getting a precise idea [26]. New developments in microscopy will hopefully bring some valuable keys for this understanding [27]-[29]. Anyhow, some general characteristics are common to all tendons and ligaments and the most important are discussed below.

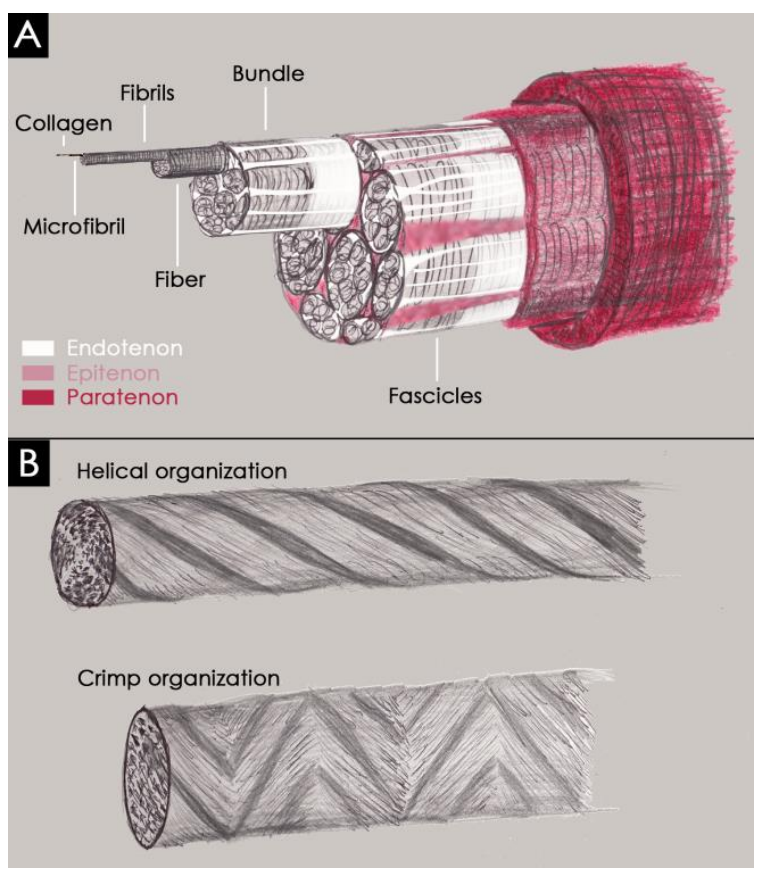

Figure 2: Schemes illustrating the major structural characteristics of extracellular matrix of tendon: (A) Hierarchical organization of tendon unit. (B) Helical and crimp organization of fascicles (resp. top and bottom).

Tendons and ligaments are organized in a hierarchical manner that starts with collagen I molecules, which, associated by five into "microfibrils", pack into fibrils [30]. The fibrils are further associated into fibers that are joined into bundles delineated by the endotenon, a fine ECM of another composition and organization. The endotenon is continuous with the surrounding connective tissues and facilitates sliding between adjacent structures. In particular, it is in continuity with the epitenon that further tights together bundles of fibers into fascicles. Depending on the tendon, fascicles may present another covering layer named "paratenon" (Figure 2A). Finally, several fascicles may be bound together to give larger units [31].

Collagen fibrils within endotenon, epitenon and paratenon are not necessarily collinear to the tendon and can be found perpendicularly oriented [32]. Those layers possibly maintain the integrity at each level from bundles to tendon. 
A

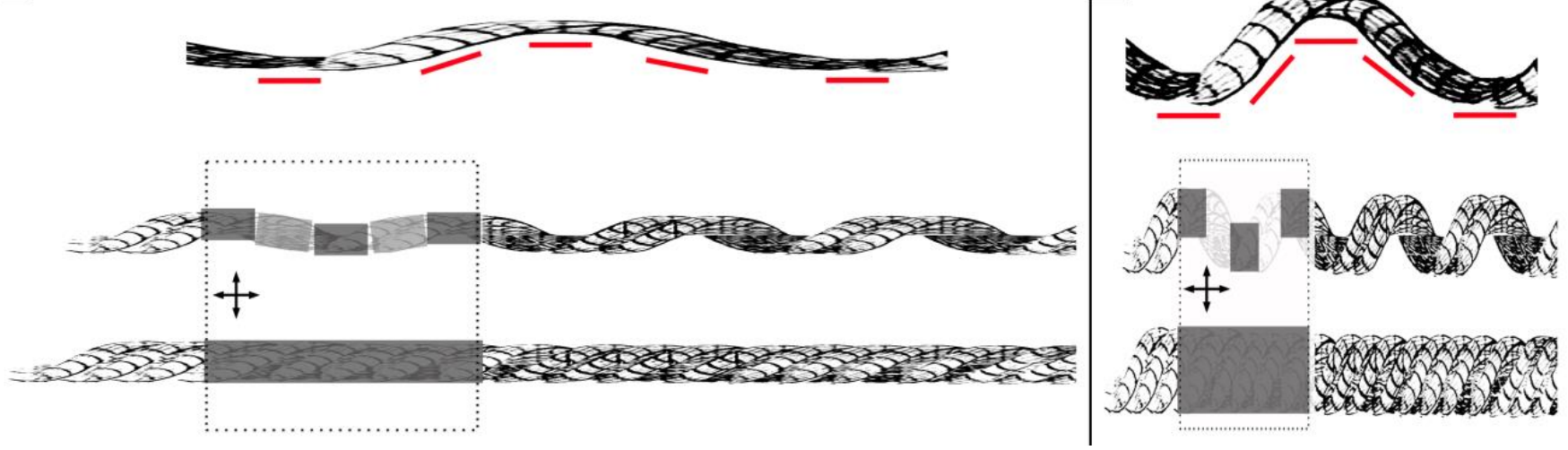

Figure 3: Scheme conciliating helix crimp and linear organization: A single stranded helix is schematized on top, a partial super-helix in the middle and a full super-helix on bottom. Boxed by the dotted line, their appearance when observed between crossed-polarizers. Crossed-arrows indicate directions of polarizers. (A) Top: The extended helical strand and beneath the projected collagen molecular orientations are represented by lines. All orientations are nearly aligned along the helix axis. Middle: The partial super-helix is represented and the molecular orientations being all nearly aligned along one polarizer, the crimp is hardly seen and the partial super-helix appears nearly dark. Bottom: the symmetry of the complete super-helix is cylindrical. The mean projection of the molecular directions sums up along the axis of the helix. The complete super-helix appears dark under crossed-polarizers. (B) Top: The molecular orientations vary along the axis of the helix and present a repeating unit of alternating orientations. Middle: The partial super-helix is represented and the molecular orientations varying as illustrated above, the crimp is clearly seen as banded pattern under crossed polarizers. Bottom: the symmetry of the complete super-helix remains cylindrical with the mean projection of the molecular directions summing up along the axis of the helix. The complete super-helix still appears dark under crossed-polarizers.

They also possibly take part in its mechanical properties. Blood and lymphatic vessels, as well as nerves, are found in the endotenon, epitenon and paratenon.

Cross-polarized optical microscopic observations of excised rat tail tendons reveal an overall alignment of the bundles along the tendon axis. They also reveal units, from 10 to $100 \mu \mathrm{m}$, with alternating oblique orientations compared to the tendon axis. This feature is referred to as "crimp" (Figure 2B bottom). Evidence of this crimp was further observed by atomic force and electron microscopies (scanning and transmission) [33][34]. The crimp was suggested to be a natural shock-absorber and to play a role in elastic recoil [35].

Shah et al. (1982) reported that the crimp was only observed at day $16^{\text {th }}$ during the embryonic development of chick tarsus metatarsus region. The appearance of the crimp correlated with a high increase of collagen content between day $14^{\text {th }}$ and day $16^{\text {th }}$ [36]. This suggests the crimp to be highly related to the presence of collagen fibrils. On the other hand, for Herchenhan et al., (2012) tenocytes, cells found inside tendon, induce formation of crimps [37]. Their conclusion relies on the fact that, knocking down cells using polyoxyethylene (9-10) p-t-octyl phénol (TX100) within a biomaterial construct presenting a crimp, induces its loss. However, the authors do not take into account the fact that TX-100 also interacts with collagen and even destabilizes fibrils, possibly contributing to the loss of the crimp [38][39].

In addition to the overall alignment and the crimp, Vidal et al. (2003) analyzed under crossed polarizers transversal sections of tendons and showed that fascicles presented a helical organization along the tendon axis [40] (Figure 2B top). This raises the question on how the crimp structure can be compatible with both a cylindrical symmetry and a helical organization. Geometrically speaking, one way to explain the crimp would be an over-winding of a helical organization. In vivo, under tension, it would be extended and fascicles would appear quasi collinear with the direction of the tendon. No "crimp" would be detected (Figure 3A). However, when tendons are relaxed and/or excised, the linear tension would decrease and the over-winding would collapse on itself while still being constrained transversally by the $90^{\circ}$ transverse collagen sheath. The crimp would thus appear (Figure 3B).

Mechanical tests made on tendon clearly show the difference of mechanical behaviors during the elongation of the crimp and after [35]. Computational modeling best fits the mechanical experimental data when a helical arrangement is injected into the models [41]. Reese et al. (2010) further improved the fit by combining a wavy pattern with a super-helical arrangement [42]. This data comforts the idea of a super-helical structure.

It has been shown that super-twisted organizations could be spontaneously generated in liquid-crystals [43]. Knowing that collagen forms different liquid crystal phases [44][45][46] that are subject to physico-chemical parameters [47], it is not excluded, although there is no proof yet, that the over-winding helical organization of tendon may also result from simple physical-chemical laws. Most probably, cells and physico-chemistry work hand in hand. 
Modifications upon aging, injury and recovery have been studied at different levels: biochemical, fibrils (diameter, orientation) and crimp (presence or not, period) [21][48]. Here, again, it seems that there is not a unique scheme of evolution with different observations being made depending on tissues and/or species. To further highlight the complexity of the living tissues, their studies and the different routes to achieve their healing, reconstruction or replacement, it should be noted that control tendons, which are generally contralateral tendons, also see their characteristics being modified, possibly due to stress and postural changes during healing process.

Tendon wound healing process is characterized by three different stages: inflammation, repair, and remodeling [5], [49]. After injury there is a high release in growth factors, cytokines, and an increase in the expression of tendonassociated molecules, which cellular origins are still difficult to trace back [50]. During the repair phase, collagen type III is mainly synthesized, leading to the formation of a scar tissue with increased cross section area. During matrix remodeling, which can last months to years, collagen type I synthesis is increased and the newly formed fibers are aligned along the longitudinal axis of the tendon. The tissue obtained often displays reduced mechanical properties due to the presence of disorganized collagen, as well as improper non-collagenous molecules and exogenous cells recruited at the wound site. These cells can lead to the formation of fibrous peritendinous adhesions with the surrounding tissue, impairing the normal stress transmission and hence the restoration of normally aligned collagen fibers [1].

The ultimate tendon repair is based on several requirements. The prior physiological criteria include, among others, the initial strength recovery, the joint gliding, the re-rupture avoidance and the shorter returntime to activity. Early active mobilization of the repaired tendon is advocated to improve those properties [19]. It was also proved that this early post-surgery stimulation increases the collagen type I cell production and that the quick tension restoration induces the parallel alignment of this renewed collagen [51]. In the following part, the different strategies clinically used from sutures to decellularized matrices will be described.

\section{CURRENT CLINICAL STRATEGIES}

The route chosen to induce healing of the tendon must take into account the gravity of the injury. From chronic tendon injury to tendon tears, the first objective is to reduce the patient's pain due to the tissue inflammation with specific drugs and with rehabilitation exercise [52], [53]. Then, emerging treatments consist in delivering growth factors through autologous whole blood or platelet rich plasma (PRP). Although in vitro studies show that these injections impact favorably the collagen production and degradation mechanisms [54], their use in clinical cases are controversial. Indeed, several questions regarding the injection frequency, volume, concentration etc. still remain open.
For acute tendon injury, the treatment depends on the lesion severity. If the gap between the two tendon extremities is less than $3 \mathrm{~mm}$, the self-healing mechanism is engaged [55]. For larger injuries, if the joint motion is altered or even completely lost then surgery is needed. The length of the gap will determine the approach to be adopted. If the gap is less than $3 \mathrm{~cm}$, suture techniques are required to rejoin the tendon. In the case of Achilles tendon, the conciliation of its 2 ends requires a great force. This is why, if the rupture is in an easy access location, surgeons use some devices as bone clamp [56] or Integra ${ }^{\mathrm{TM}}$ Achillon ${ }^{\circledR}$ system [57], [58], to join the tendon and then suture it. It should be kept in mind that the more handled is the injured tendon the more severe are the tissue trauma and adhesion. Wang et al. (2006) have even shown in a murine model that the suture directly affects the cellular healing process. The acellular zone does not heal and present inflammatory signs [59].

For gaps larger than $3 \mathrm{~cm}$, augmentation of the ruptured tendon with additional implants or grafts is recommended [56]. Several types of devices from metallic implants to synthetic grafts are commercially available and already used by clinicians (Table 1, [60]).

\subsection{Sutures}

Three methods of tendon suturing have been developed and optimized: the non-grasping, the grasping and the locking anchors. The non-grasping method was first performed on finger flexor tendon by Bunnell in 1918 [19] (Figure 4A). This technique consists in looping the anchor around the epitenon. As a consequence, no collagen fibers bundles are injured. On the contrary, the methods based on grasping, (opened loop, Figure 4B) and locking anchors (closed loop, Figure 4C) pinch the collagen fibers.
A

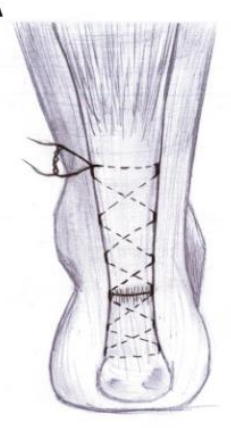

B

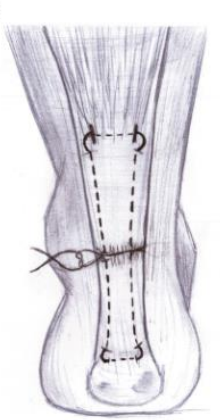

C

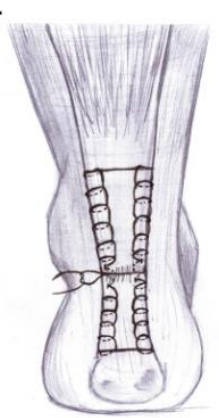

Figure 4: Scheme of the three sutures commonly used to repair tendon (Achilles tendon example in back view). (A): the non-grasping suture (Bunnell) consisting in looping the anchor around the epitenon. (B): the grasping suture (Kessler) based on 4 opened loops, which pinch collagen fibers. (C): The locking suture (Krackow) made of several closed loops.

However, those two techniques bring better mechanical properties and gapping resistance to the tendon. They took the name of their authors Kessler for the grasping suture and Krakow for the locking one. The last one is assumed to be the more effective and is constantly being improved [61]. 


\begin{tabular}{|c|c|c|c|c|}
\hline Type & Name & Source & Company & Ref \\
\hline \multirow{2}{*}{ 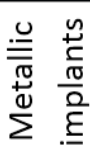 } & Teno Fix ${ }^{\circledR}$ & Stainless steel & Ortheon Medical, Winter Park (USA) & $\begin{array}{l}\text { [Wolfe } \\
\text { 2007] }\end{array}$ \\
\hline & Tenolig $^{\odot}$ & $\begin{array}{l}\text { Stainless steel (with } \\
\text { Dacron }{ }^{\circledR} \text { fibers) }\end{array}$ & FH Orthopedics, (FR) & $\begin{array}{c}{[\text { Lacoste }} \\
2014]\end{array}$ \\
\hline \multirow{10}{*}{ 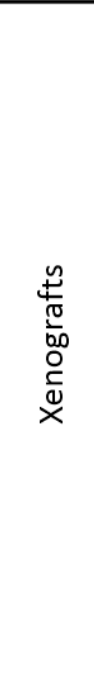 } & Bio-Blanket $^{\circledR}$ & Bovine dermis & Kensey Nash Corp. (USA) & \multirow{3}{*}{$\begin{array}{c}\text { [Gomes } \\
2015]\end{array}$} \\
\hline & Conexa $^{\oplus}$ & Porcine dermis & Tornier/Wright Medicals (TN) & \\
\hline & CuffPatch $^{\oplus}$ & Porcine SIS & $\begin{array}{l}\text { Organogenesis (MA, USA) } \\
\text { Licensed to Arthrotek(IN, USA) }\end{array}$ & \\
\hline & Inforce ${ }^{\oplus}$ Reinforcement Matrix & Porcine dermis & IntegraLife Sciences (NJ, USA) & [Hollawell \\
\hline & OrthADAPT ${ }^{\circledR}$ & Equine pericardium & Pegasus Biologic Inc. (USA) & $\begin{array}{c}{[\text { Gomes }} \\
2015]\end{array}$ \\
\hline & Restore $^{T M}$ & Porcine SIS & DePuy Orthopedics (IN,USA) & $\begin{array}{l}{\left[\begin{array}{c}\text { Phipatana } \\
\text { kul 2009] }\end{array}\right.} \\
\end{array}$ \\
\hline & Shelhigh No-React ${ }^{\oplus}$ Encuff Patch & $\begin{array}{l}\text { Bovine or porcine } \\
\text { pericardium }\end{array}$ & Shelhigh Inc. (NJ, USA) & $\begin{array}{c}\text { [Gomes } \\
\text { 2015] }\end{array}$ \\
\hline & TissueMend ${ }^{\circledR}$ & Bovine fetal dermis & $\begin{array}{l}\text { TEI Biosciences (MA, USA)licensed to } \\
\text { Stryker Orthopedics (NJ, USA) }\end{array}$ & $\begin{array}{l}\text { [Song } \\
2010]\end{array}$ \\
\hline & $\begin{array}{c}\text { Trellis }^{T M} \text { Collagen Ribbon/ } \\
\text { Biotape XM }\end{array}$ & Porcine dermis & Wright Medical Technology, Inc. (USA) & \begin{tabular}{|l} 
[Berlet \\
2014]/[Go \\
mes 2015]
\end{tabular} \\
\hline & Zimmer $^{\oplus}$ or Permacol ${ }^{\mathrm{TM}}$ & Porcine dermis & $\begin{array}{l}\text { Tissue Science Laboratories (MA, USA) } \\
\text { licensed to Zimmer (IN, USA) }\end{array}$ & $\begin{array}{c}\text { [Gomes } \\
\text { 2015] }\end{array}$ \\
\hline \multirow{4}{*}{$\begin{array}{l}\frac{n}{\pi} \\
\frac{0}{00} \\
\frac{0}{4} \\
\frac{1}{4}\end{array}$} & Arthroflex ${ }^{\circledast}$ & Human dermis & Arthrex, LifeNet Health Inc. (USA) & $\begin{array}{c}\text { Gomes } \\
2015]\end{array}$ \\
\hline & 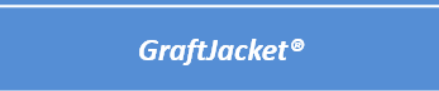 & Human dermis & Wright Medical Technology (USA) & \begin{tabular}{|c} 
[Song \\
2010, Lee \\
$2008]$
\end{tabular} \\
\hline & Matrix ${ }^{\mathrm{TM}} \mathrm{HD}$ & Human dermis & RTI Surgical (USA) & \multirow{2}{*}{$\begin{array}{l}{[\text { Gomes }} \\
2015\}\end{array}$} \\
\hline & TenSIX $^{\mathrm{TM}}$ & Human dermis & Solana, Wright Medical (USA) & \\
\hline \multirow{11}{*}{ 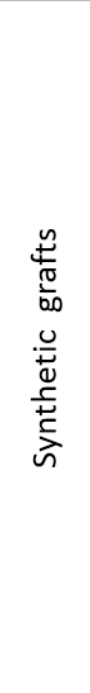 } & Artelon $^{\oplus}$ and Sportmesh ${ }^{\mathrm{TM}}$ & $\begin{array}{l}\text { (Polyurethane urea ) } \\
\text { polymer }\end{array}$ & $\begin{array}{l}\text { Artimplant AB (SWE) } \\
\text { Biomet Sports Medicine (IN, USA) }\end{array}$ & $\begin{array}{c}\text { [Shoaib } \\
\text { 2016] }\end{array}$ \\
\hline & Biomerix ${ }^{\mathrm{TM}}$ RCR Patch & $\begin{array}{l}\text { Polycarbonate } \\
\text { (polyurethane urea )with } \\
\text { polyester fibers }\end{array}$ & Biomerix (USA) & \multirow{4}{*}{$\begin{array}{c}\text { [Gomes } \\
2015]\end{array}$} \\
\hline & Gore-Tex ${ }^{\oplus}$ & Polytetrafluoroethylene & WL Gore and Associates (USA) & \\
\hline & LARS ligament & PET & LARS (FR) & \\
\hline & Leeds-Keio $^{\circ}$ or Poly-tape ${ }^{\circ}$ & $\begin{array}{l}\text { Polyester ethylene } \\
\text { terephthalate }\end{array}$ & $\begin{array}{l}\text { Xiros plc, Neoligaments (UK) } \\
\text { Yufu Itonaga Co. Ltd (JPN) }\end{array}$ & \\
\hline & Marlex ${ }^{\ominus}$ mesh & Polyethylene polymer & C R Bard (USA) & $\begin{array}{c}{[\text { Morrey }} \\
2016] \\
\end{array}$ \\
\hline & Orthocoupler ${ }^{T M}$ & PET & $\begin{array}{l}\text { bioLOGIC Corp., Surgical Energetics LLC } \\
\text { (USA) }\end{array}$ & $\begin{array}{c}\text { [Melvin } \\
\text { 2010] }\end{array}$ \\
\hline & Ortho-Tape ${ }^{\oplus}$ & PET & Neoligaments (UK) & \begin{tabular}{|c|c|c|} 
Abdullah \\
$2015]$ \\
\end{tabular} \\
\hline & Sericuff' & Silkworm silk & Serica, Allergan (USA) & \multirow{3}{*}{$\begin{array}{c}{[\text { Gomes }} \\
2015]\end{array}$} \\
\hline & STR GRAFT $^{\text {TM }}$ & Poly-L-Lactide & Soft Tissue Regeneration Inc. (USA) & \\
\hline & $\mathrm{X}$-repair ${ }^{\mathrm{TM}} \mathrm{X}$-repair-SL & Poly-L-Lactide & Synthasome (USA) & \\
\hline
\end{tabular}

Table 1: Commercially available grafts or implants for tendon repair. The devices written in bold italic are detailed in sections 3.2 and 3.3 .

Several fibers made of polyester (Ethibond®), nylon, polypropylene or a combination of ethylene glycol and terephthalic acid (Dacron ${ }^{\circledR)}$ are already clinically used for suture alone. They are non-resorbable as they have to 
maintain more than one year the end-to-end tendon extremities [19]. Other materials have been developed for suture augmentation, which is a different approach. Schliemman et al. (2015) compared the reconstruction of a tendon with a polydioxanone (PDS) or cable wire augmentation and with suture anchor repair alone. They showed that suture augmentation in both cases provides less elongation and higher loads (almost a 1.5 factor) than the simple suture [62]. A negative aspect of cable wires is that a second surgery is needed to remove them.

Alternative methods have been proposed to avoid the use of sutures. Hohendorff et al. (2008) compared post-surgery results of Achilles tendon rupture treated either with fibrin glue or sutures. They noted that both strategies reached almost the same results. Moreover, fewer complications were observed for the fibrin glue cohort [63]. Rose et al. (2014) also worked on the biological tissue gluing. They used solutions of silica nanoparticles (NPs) to glue mismatched tissue. They tested it in vitro on a piece of calf liver with a created gap of $2 \mathrm{~cm}$. They glued the two ends and keep it under finger pressure during $30 \mathrm{~s}$ [64]. They observed that the two parts of the liver remained attached and that the glue did not affect the rigidity or the permeability of the tissue. This second approach is very promising as it is quite simple and fast to implement. It must be tested on tendon to know if the bonds created with the silica NPs are strong enough to support physiological loads as applied in Achilles tendon sites for months in vivo.

\subsection{Metallic implants}

Some other researchers have developed metallic implants to achieve tendon repair with the best mechanical properties.

Erol et al. (2007) developed an implant made of stainless steel wires with different spiral-shaped structures on sheep cadaveric Achilles tendons [65]. Briefly, the prostheses are composed of a coiled wire head, which hooks the tendon, and a wire passing through it to join the head to the other tendon end or bone. They also compared their implant with classical sutures. In some cases, they observed the breaking of the tendon-implant holding point and the fibering of tendon's ends, raising the problem of the material elastic properties. If the material is too stiff compared to the tendon, the rupture of the anchor will occur. To have the best mechanical properties, it is essential to use materials with the same range of elastic modulus as tendon. In their preliminary study, they obtained good mechanical results compared to sutures alone. But authors advised to use this kind of device only for bone-tendon repair. Ağır et al. (2014) also investigated this kind of metallic implant. In their study, they used stainless steel wires but designed it with several loops [66]. The wire is applied from outside and allows the transversal anchoring of metallic pins in it. Here again, some limitations of the device are explained: these implants cannot be used for hand injuries and are more suitable for larger body tendons as Achilles tendons.
Metallic devices such as the Teno Fix ${ }^{\circledR}[67]$ or Tenolig ${ }^{\circledR}$ [68] are already commercially available. They were tested on cadaveric tendons and on patients respectively. Teno Fix ${ }^{\circledR}$ was compared with conventional sutures and no biomechanical improvement was shown switching from one to the other. Tenolig® exhibits different advantages such as the use of percutaneous surgery for the device positioning with ultrasonography monitoring to target the two Achilles tendon ends, very small wound scares and complications occuring only for 1 over 75 patients. The return time to sport was estimated to be 9 months. This kind of metallic implant is not largely used in clinical practice, as studies evaluating their effective improvement compared to classic sutures are still rare. Moreover, several limitations such as tearing of the site repair have been highlighted as mentioned above. Extensive improvements of these techniques are needed before becoming a common and viable strategy.

If the tendon injury has been neglected or if the site of injury has a poor quality due to tendinopathy, sutures or implants are not sufficient anymore to repair it [69]. Furthermore, to avoid the re-rupture, a reinforcement of the site is needed. To meet these objectives, grafts can be used. The tendon augmentation with grafts consists in adding a matrix either around the defect and then suturing it (onlay surgery), or in the ruptured tendon and then closing it with suture inside (inlay surgery). The combination of the classic sutures, which join the two tendon extremities, with the graft, may improve tendon repair. The grafts can come from different origins: the patient himself (autograft), another human being (allograft), animals (xenograft) or from synthetic materials. These different grafts are successively described in the following part.

\subsection{Grafts}

Autografts.

Sophisticated surgical procedures have been elaborated to overcome large tendon defects with patient's own "material". Three kinds of procedures more or less invasive allow accessing the tendon: open, mid-open and percutaneous. Beskin et al. (1987) compared four "open" techniques on 42 patients suffering from Achilles tendon rupture: Bunnell or Kessler sutures, "three bundle", and augmentation, either with the plantaris or with the peroneus brevis tendon [70]. These last two methods consist in using local tendon transfer to reinforce the Achilles tendon. The four techniques show promising results as 85 to $92 \%$ of patients return to normal long-term activity after the surgery. However, in each case, a single long longitudinal excision is performed which is very invasive, urging some clinicians to develop less invasive techniques. Carmont et al. (2007) also used the peroneus brevis tendon to reconstruct Achilles tendon [71]. Contrary to Beskin et al., they did two para-midline incisions. Skin wounds are clearly smaller and skin integrity is preserved. Moreover, this allows preserving the surrounded tissues (tendon sheath) and may improve tendon's healing. To follow through, other autologous sources for reconstruction can be 
recruited. Ebied et al. (2016) repaired Achilles tendons thanks to free semi-tendinous tendon grafts from upper muscles [72]. Shewy et al. (2009) used two intratendinous flaps from the proximal gastrocnemius-soleus complex [73]. Briefly, they created two flaps in the musculotendinous junction and passed them through the Achilles tendon gap. They fixed the flaps extremities to the calcaneus (bone). Few complications were observed as wound gapping or infection, and long pain after surgery. However, this technique showed good results as patients recovered their pre-injury sporting activity level.

The main advantage of these two surgeries is the use of highly vascularized tissues in a site close to the injured tendon, but less invasive incisions are recommended for the future. Autografts present several key strengths such as absence of foreign body response, conservation of native mechanical properties and vascularization continuity. The main inconvenient is the risk of damaging the donor site tissue and thus creating new lesions. Moreover, the neotendon reconstructed with surrounding tendons or muscles parts is thicker than the native one. This can lead to unsightly aspect repair and to patient discomfort on the repair site.

Other strategies to repair injured tendons have been developed to avoid creating more lesions in patients. Tendon augmentation with xeno- or allograft may be good candidates for this purpose.

\section{Xeno- and allografts}

Xenografts are tissues or organs coming from other species that are pre-decellularized. Porcine decellularized small intestine submucosa (SIS) is the most commonly used xenograft. Several clinical studies have been performed to assess their effectiveness for tendon repair augmentation. Phipatanakul et al. (2009) used SIS (Restore ${ }^{\mathrm{TM}}$ ) for rotator cuff repair [74]. As repairs were not convincing and as some complications (infections, skin reactions) were observed, authors did not recommend SIS for such repair augmentation. Sclamberg et al. (2004) came also to the same conclusion for this repair area as 5 over 11 patients presented worse results after the surgery [75]. Clinicians are quite unanimous on this issue. However, SIS may be adapted for tendons in other locations such as the foot or ankle as only $6 \%$ of the patients showed complications such as re-tear or patch failure.

Other sources of xenografts are also used. Berlet et al. (2014) tested the Trellis ${ }^{\mathrm{TM}}$ device (a decellularized, freeze dried and sterilized porcine dermis), in a ribbon form on human cadaveric feet [76]. They created tendon defects greater than $5 \mathrm{~cm}$. The tensile testing showed that in most cases, the suture failed first. As the tendon ends are not joined anymore, the load is only borne by the graft. Thus, in comparison with suture alone, the Trellis ${ }^{\mathrm{TM}}$ augmentation enhanced strength of Achilles tendon repair.

Other strategies, based on allografts, have been developed to overcome some rejection or infection reactions. Allografts are ECMs mostly coming from human dermis or
SIS. Song et al. (2010) compared two commercially available devices on a cadaveric sheep model [77]. The first one is a xenograft named TissueMend ${ }^{\circledR}$, which is derived from fetal bovine dermis and the second one, an allograft named GraftJacket ${ }^{\circledR}$ from human skin. The authors remind that grafts of dermis origin have better mechanical properties than matrices derived from SIS that were previously described. TissueMend ${ }^{\circledR}$ and GrafJacket ${ }^{\circledR}$ presented almost the same strength. They both improved tendon repair compared to suture alone. Lee et al. (2008) also used GraftJacket ${ }^{\circledR}$ matrix to augment tendon repair [78]. Clinical tests on Achilles tendon rupture were performed. At 3 months, patients recovered full range of motion and no re-rupture happened. The return-time to activity was about 12 weeks, which is quite encouraging.

Rather than choosing between xenografts and allografts, Hollawell et al. (2015) decided to combine them for Achilles tendon repair [79] . They used the allograft to span the gap between the two tendon ends and the xenograft (Inforce ${ }^{\circledR}$ Reinforcement Matrix) to secure the repair site. This graft combination improved the mechanical properties and physiological function, and patient pain was reduced. Some further investigations of this new strategy must be performed to better quantify its benefits.

Those acellular matrices either from animal or human origin show great advantages, overcoming the host reaction concerns and leading to good mechanical properties. Herbert et al. (2015) evaluated different decellularization processes needed to obtain such materials [80]. They studied the effect of using acetone or chloroform as fat agent reduction and antibiotics or peracetic acid as biodecontaminants. They showed that the tensile strength and Young modulus of acellular porcine super flexor tendons are in the same range as the native one before the decellularization. However, this process altered the matrices properties at the low strains in the toe region where the crimp should play its shock absorber role. A potential way to overcome this problem is to reproduce this wavy structure. Branch et al. (2011) adopted this strategy with allograft for Achilles tendon repair [81]. They cut a human dermal acellular mesh in a z-wave shape, which finally looked like an accordion. They performed inlay surgery with a "strip and shoelace" weave. No re-rupture occurred and only one over the 3 case reports presented adhesion with the surrounding tissues.

Regarding the loss of cellular material due to the decellularization process, cell-based therapy combined with allografts emerged. Gaspar et al. (2015) reviewed the different cell strategies [82]. Before being implanted on the tendon injury sites, grafts can be sown with cell suspension to enhance tendon regeneration. They highlighted the fact that the cell type chosen is crucial. Indeed, tenocytes or dermal fibroblasts are already differentiated, but their available quantity is limited. Progenitor stem cells overcome this issue, but can lead to bone ectopic formation. Finally, induced pluripotent stem cells may also be used on grafts. However, they raised the safety and efficiency problems. Güngormüs et al. (2016) used tenocytes and seeded them on decellularized rat tendons 
[83]. Finally, they implanted the cell-seeded scaffold in a rat model. No immune reaction occurred and their other results suggested that this scaffold improve mechanical properties of the repair.

Even if xeno- and allografts present some advantages, the matrix alteration due to the decellularization process is a problematic issue as it alters mechanical properties and leads to antigenic response [84]. Since it is essential to augment tendon with grafts having similar range of strength, synthetic grafts have been developed and are currently used in clinical practice.

\section{$\underline{\text { Synthetic grafts }}$}

Two categories of synthetic grafts are used to augment tendon. The non-resorbable grafts persist in the body and act as a substitute to overcome the lack of tissue. On the contrary, resorbable grafts are degraded by the body and support the fibrous ingrowth [85].

Non-resorbable grafts are commonly made of synthetic polymers such as polyester (Dacron $\left.{ }^{\circledR}\right)$, polytetrafluoroethylene (PTFE or Teflon ${ }^{\circledR)}$ [86], and silicone rubber [87]. Such materials are already clinically used. Morrey et al. (2016) evaluated non resorbable polypropylene mesh commercially available (Marlex $\left.{ }^{\circledR}\right)$ on 8 quadriceps tendons ruptures (knee) [88]. No re-rupture occurrence and good range of motion were the main advantages of this synthetic augmentation. As they tested it on a small cohort, with no mechanical evaluation, further studies are needed. Abdullah et al. (2015) evaluated the use of polyethylene teraphtalate (PET) mesh called OrthoTape ${ }^{\circledR}$ [89]. They explored this new device on two patients who needed hand surgery because of massive tendon loss. Promising physiological results were shown. Melvin et al. (2010) developed their own device Orthocoupler®, made of 32 bundles of thousand PET fibers [90]. They implanted it in a goat model. Sixty days after the surgery failure forces for the specimens with the synthetic graft were 2.5 times higher than for sutures in the control group. Sutures were too fragile compared to the Orthocoupler® which is anchored and sutured in the muscle. It allows reinforcing the musculo-tendinous junction.

Finally, another criteria is the prevention of the tendon sheath adhesion. Non-resorbable grafts made of Teflon seem to be the appropriate candidates. Indeed, Williams et al. (1964) tested them on a dog model and compared them with autologous grafts [86]. Adhesions with the surrounding tissues were clearly observed for autogenous grafts, whereas Teflon graft surfaces glide and allow free joint motion. However, they reported some surgery problems as the solid anchoring of the Teflon grafts on tendon.

Non-resorbable grafts present some advantages such as their biocompatibility, their strength and the absence of adhesion with the tendon site. Nevertheless, they cannot be degraded, and are generally complicated to implement.

Resorbable grafts may overcome some of those issues. They can be composed of carbon ([91], [92]), polyglactin
[93], polyglycolic acid (Dexon®) [94], or polylactic acid [95]. In the 1970s, Jenkins et al. (1980) investigated flexible carbon implants for ligament or tendon injuries. Special affinity of the living tissue with carbon was observed [91]. Moreover, carbon based scaffolds enhance the mechanical properties of the tendon and improve the alignment of collagen neo matrix. However, fragmentation of this kind of material often occurs and may lead to some irritation of the joint. Finally, they should not to be used close to metallic implants as they can react together. To overcome these drawbacks, Alexander et al. (1983) tried to coat carbon implants with polylactic acid but could not reduce the fragmentation process [96].

In this way, Cao et al. (2001) used unwoven polyglycolic acid fibers, which they assembled in a cord shape and wrapped with acellular intestinal submucosa membrane [97]. Tenocytes were cultured on it. Then, they created a $2.5 \mathrm{~cm}$ long defect in the second digital flexor profundus tendon of hen and repaired it with the cell-scaffold. They harvested the specimens at 8, 12 and 14 weeks and performed histological observations. The longer the graft stayed in the body, the better were the biomechanical properties. The authors suggested that a minimum time was required for a good tissue remodeling of the tendon. Histological results showed that the neo-tendon contained a large amount of tenocytes and presented its own structure, easy to distinguish from native tendon.

Synthetic polymer scaffolds can also be designed as a tissue mesh. Shoaib et al. (2016) performed surgical repair in 7 patients suffering from symptomatic chronic Achilles tendon rupture with a bio-absorbable polyurethane polymer device (Artelon ${ }^{\circledR}$ ) [98]. Artelon ${ }^{\circledR}$ can be seen as the resorbable equivalent of the Ortho-Tape ${ }^{\circledR}$ previously described. They compared this synthetic tendon augmentation to the Krakow suture alone. Better results were shown with the Artelon ${ }^{\circledR}$ graft. The authors also suggested that this device could be used for defect larger than $5 \mathrm{~cm}$. Finally, they recommended combining it with non-resorbable suture in order to secure the augmentation over the years.

We have seen that synthetic grafts show promising results for tendon repair and in particular for the mechanical properties. However, some concerns persist as they may lead to foreign body response. This is also the same for xeno-allografts, and in the case of autografts, new lesions are created that may lead to secondary surgery in case of local degradation. Clinical practices or devices to repair tendon get closer to the ultimate goal, but they often lack specific criteria as strength or body tolerance. This is why some new scaffolds based on biocomponents are currently being developed. Such engineering is not straight-forward and needs to meet several strict specifications that we will discuss below.

\section{SCAFFOLD DESIGN SPECIFICATIONS FOR TENDON REGENERATION}

Tendon being such a specific tissue, with multiscale order and high mechanical solicitations, scaffolds for 
reconstruction must meet several requirements. These are dependent on the site aimed for reconstruction. Indeed, tendon size and shape can vary greatly, in function of the location in the body. Whereas rotator cuff and patellar tendons are sheet-like, length and width being in the same order and much greater than the thickness, Achilles tendons are rather unidimensional, in a rope-like manner shape [99]. Typical dimensions are given in Table 2. Mechanical properties can also vary according to sites and persons, with Young modulus ranging from 0.5 to $1.9 \mathrm{GPa}$, ultimate tensile strength from 50 to $120 \mathrm{MPa}$ and strain at break between 5 and 20\% [100] [101]. Scaffolds must meet as much as possible these properties to resist solicitations and promote cell differentiation [102]. Even though tendons and ligaments are sometimes indiscriminately named in papers given their similarities, they do exhibit differences when it comes to mechanical properties. Ligaments are usually not as stiff (modulus from 5 to $450 \mathrm{MPa}$ ) and strong (UTS between 1 and $50 \mathrm{MPa}$ ) as tendons and are more elastic (strain at break from 10 to $40 \%$ ) [101]. Another specificity that the scaffolds must mimic is the uniaxial structure of tendons, aligned along the direction of load. To obtain neo-tendons by promoting cell alignment and differentiation, scaffolds should mimic this anisotropy. The influence of scaffold anisotropy has been widely investigated, by using microgrooves in the micrometer scale for instance [103][104]. Scaffold alignment may be important down to $100 \mathrm{~nm}$, based on the work of Van Delft and co-workers [105].

Scaffolds for reconstruction must also comply with general specifications for regenerative scaffolds. Biocompatibility is an obvious specification but its definition is not straightforward and has evolved with time. Now, it goes further than the old definition, i.e. the absence of immune rejection or toxicity, called "bio-tolerable" by Mertz [106], adding "the ability of a device material to perform with an appropriate host response in a specific situation" [107]. Scaffolds should not be inert to the body but bioactive, promoting cell adherence and proliferation. Scaffold porosity is here paramount to ensure exchanges and cell penetration. Besides, the scaffold must be regenerative, enabling cell to differentiate and adopt the relevant phenotype to reconstruct the ECM. Many parameters are at stake here such as mechanical properties of the scaffold, its structure and alignment as well as chemical cues [102] of the ECM or growth factors. To allow good regeneration, the scaffold should at least be biodegradable or even better, bioresorbable, based on definitions given by Vert [108]. This includes the degradation and the elimination of the polymers and by-products. Time of degradation and the subsequent change in mechanical properties are also crucial for tendon reconstruction but very seldom investigated due to the complexity of such a study. To assess the question, works on small intestinal submucosa (SIS) in canine Achilles tendon repair, carried by Badylak et al. (1995) and then Gilbert et al. (2007) are valuable. Badylak et al. (1995) reported full use of the injured leg by the dogs after 9 to 13 weeks and recovery of injured tendon strength after 12 weeks as assessed by tensile testing [109]. Degradation rate of SIS was investigated by Gilbert et al. using carbon 14 measurements, showing 60\% loss after 4 weeks and

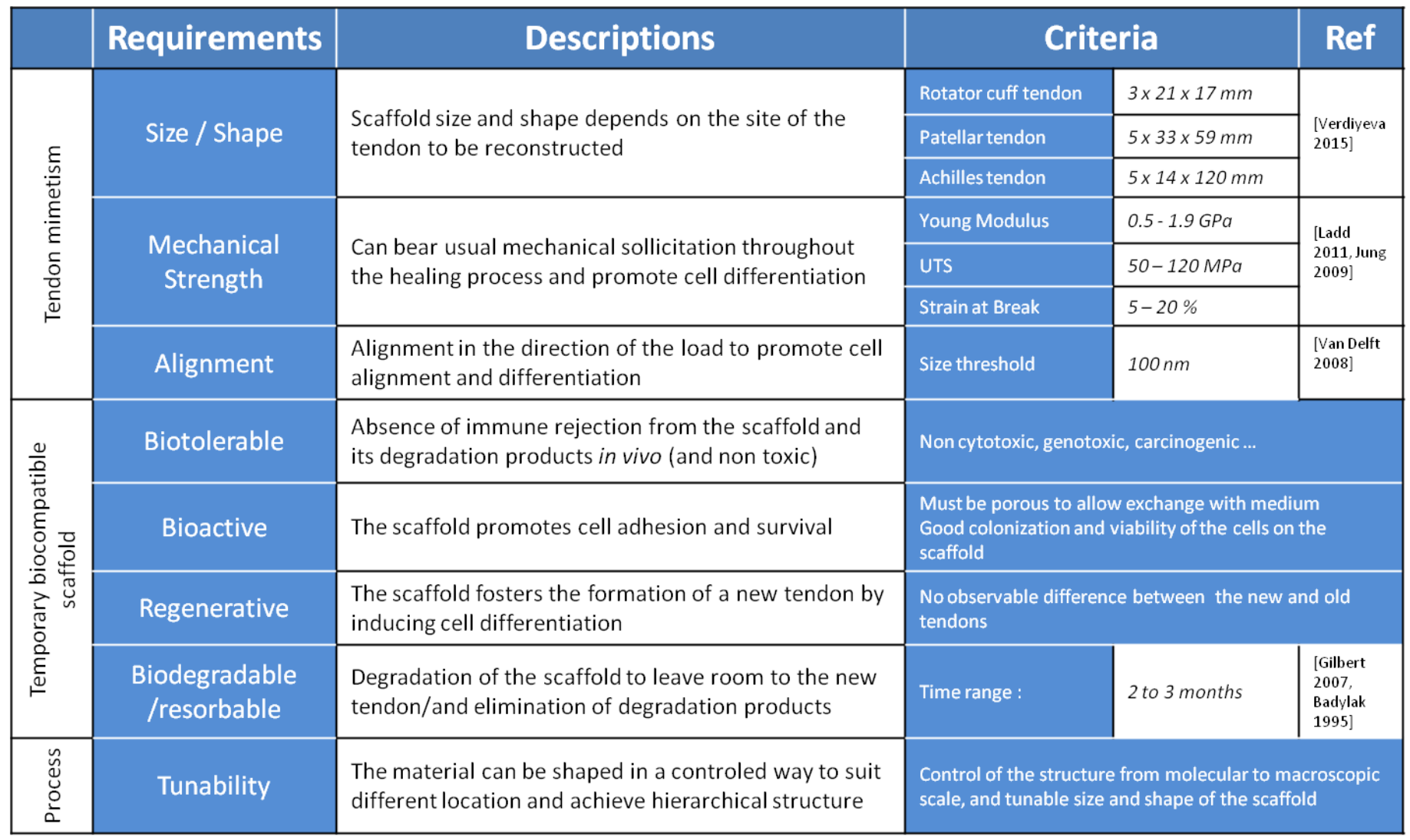

Table 2: Requirements for an ideal scaffold for tendon repair with description and quantitative criteria when assessable. 
total degradation after 2 months [110]. Thus, we can hypothesize that time span aimed for degradation should be around two months and that, after degradation of the scaffold, recovery and strengthening continue in the month scale.

Last but not least is the processability of the material. This factor is key to meet the specifications listed above and remains one of the main challenges for biomaterials, as the processing should not degrade their properties.

In this review, we will focus on the use of collagen I for tendon reconstruction as it is the main component of tendons and because it is biocompatible and degraded by enzyme with low inflammatory response [111][112]. It also promotes cell adhesion [113][114] and differentiation [102], and is one of the most favorable biomaterials for cell survival compared to cheap and easy to use alginate for instance, or to chitosan [115]. It is thus a promising material that fuels much innovative research [116].

\section{COLLAGEN BASED TECHNIQUES}

As collagen I fulfills the requirements for regenerative scaffolds listed in Table 2, the main challenge is to process it to obtain significant mechanical properties and structure for tendon repair. This section will describe collagen-based techniques, which favor the production of anisotropic complex architectures, with a particular emphasis on collagen alignment at multiple length scales to better mimic tendon structure. Although promising results for tendon repair have been obtained with isotropic materials such as collagen sponges [117], the focus will be laid on the development of scaffolds which 3D organization aims at providing mechanical support and cell guidance for

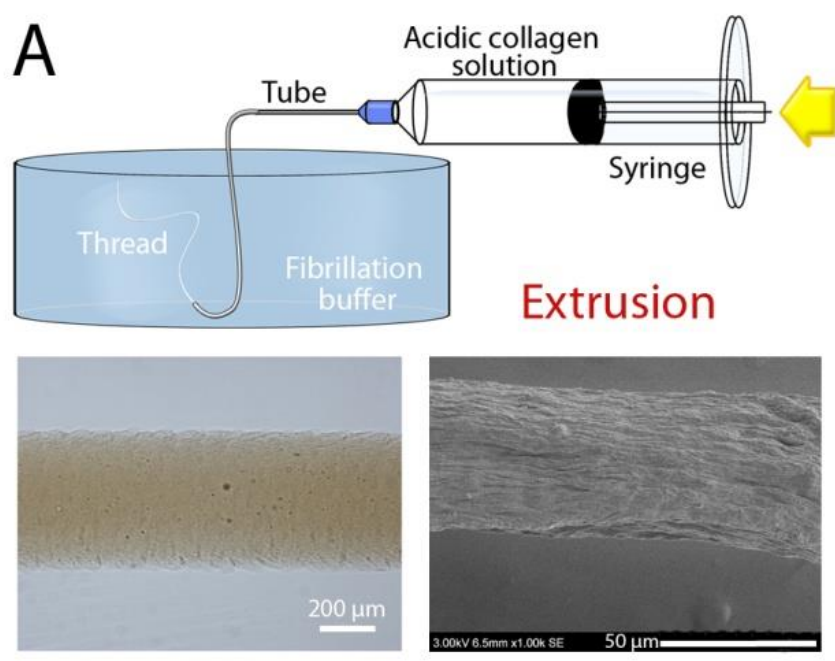

regeneration.

\subsection{Extrusion}

The extrusion process consists in forcing a material or a solution to pass through a die, giving its shape to the resulting extrudate. This method provides bars, tubes or fibers with a high production rate (few $\mathrm{cm} / \mathrm{s}$ [118]). Collagen solution extrusion was first developed in the 1960s to create new biosutures for ophthalmic surgeries [119]. Since then, the potential of this molecule was highlighted leading to its widespread use in tissue engineering. Collagen solution extrusion is quite easy to implement requiring only a syringe, a needle or tubing, a collecting bath and a device to control the flow rate (syringe pump) (Figure 5A). Basically, to produce collagen threads the syringe is filled with a collagen solution and mounted in the syringe pump. Then, the solution will pass through the tubing and will go out in a bath containing the fibrillogenesis buffer. Finally, some other post-production processes can be performed [118], [120]-[126]. Selfassembly of collagen may occur either with a $\mathrm{pH}$ transition when using an acidic collagen solution and a basic to neutral $\mathrm{pH}$ buffer, or through a temperature jump for cooled neutral collagen solution. In most studies, the collagen is extracted from rat tail (RTT) or bovine Achilles tendons (BAT). Zeugolis et al. (2008) compared the properties of threads made of RTT or BAT acidic collagen [121]. By scanning electron microscopy, they observed no significant differences in the substructure of the collagen fibers in the two kinds of threads. Collagen concentration of solution commonly used ranges from $5 \mathrm{mg} / \mathrm{mL}$ to $30 \mathrm{mg} / \mathrm{mL}$ in acidic conditions $(\mathrm{pH}=2)$ [118], [121], [123], [125]-[127]. For the fibrillogenesis buffer, the same basis is found in different studies: $135 \mathrm{mM}$ of $\mathrm{NaCl}, 30 \mathrm{mM}$ of TES

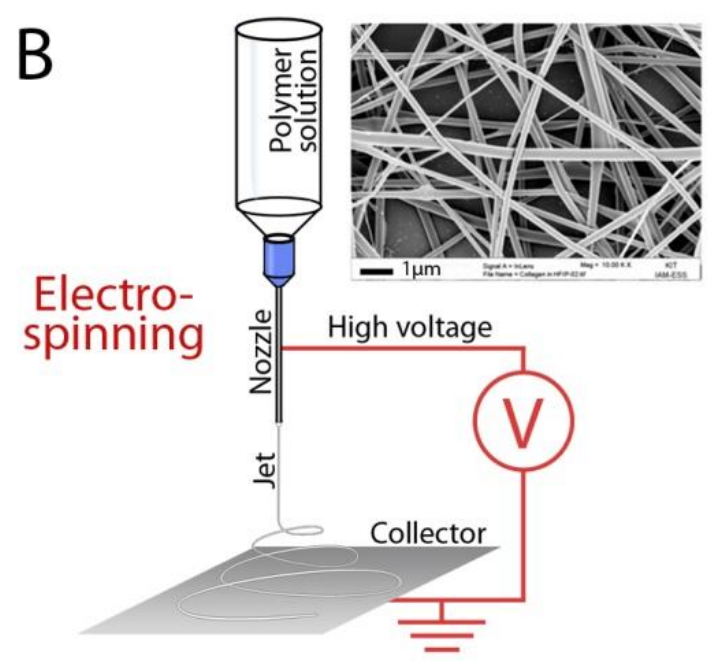

Figure 5: Schematics and resulting scaffolds of extrusion (A) and electrospinning (B) techniques. (A) Top: Schematic of the extrusion protocol where acidic collagen solution held in the syringe is forced to pass through the tubing and arrives in the fibrillogenesis buffer which induces the thread formation. Bottom: collagen thread extruded from an acidic solution at 30 $\mathrm{mg} / \mathrm{mL}$ observed under optical microscope (left) and under scanning electron microscope (right) (Authors, non-published work). (B) Schematic of the electrospinning protocol where a high voltage is applied between the nozzle and the collector, forming a jet of the polymer solution that dries into fiber. Inset: Resulting fibrous mat from a solution in 1,1,1,3,3,3-hexafluoro-2-propanol (Adapted with permission from Bürck et al. (2013) [133]. Copyright 2016 American Chemical Society). 
(tris(hydroxylmethyl)methyl-2-aminoethane sulphonic acid) and $30 \mathrm{mM}$ sodium phosphate dibasic with a resulting $\mathrm{pH}$ of 7.5 [122], [123], [125], [126]. Other buffers as phosphate saline buffer (PBS) [124] or polyethylene glycol in sodium phosphate dibasic and monobasic [118] are also used. Characteristic dimensions of collagen threads, obtained by this technique, range from $100 \mu \mathrm{m}$ to $1 \mathrm{~mm}$ for wet diameter and around $20 \mu \mathrm{m}$ to $100 \mu \mathrm{m}$ after drying [118], [122], [123], [125]. The length depends on the syringe volume capacity and the inner diameter of the tubing. In general, the mean thread length obtained by this technique ranges from few centimeters to about one meter. Mechanical properties of collagen strands have been measured in a routine manner for dry conditions and, less frequently, in wet conditions. Cornwell et al. (2007) measured Young modulus of wet collagen fibers around 4 $\mathrm{MPa}$ [127]. Regarding the elastic modulus of native tendon, those fibers are between 2 and 3 orders of magnitude "weaker". For the ultimate tensile strength (UTS), Cavallaro et al. (1994) [118], Cornwell et al. (2007) [127] and Dunn et al. (1993) [125] obtained results ranging from 1.2 to $10 \mathrm{MPa}$. Dunn et al. (1993) also observed that UTS decreases when the fiber diameter increases. So, in wet conditions, which mimics physiological environment, mechanical properties of collagen fibers are still far from that of native tendon (Table 2). This is why different crosslinking (CXL) agents are commonly used to improve those characteristics. Cross-linking process consists in creating new bonds between collagen molecules with chemical species or external excitation sources. The most commonly used on collagen threads are glutaraldehyde, carbodiimide (EDC), cyanamide, hydroxysuccinimide (NHS) and dehydrothermal treatment (DHT), simple drying process, or ultra violet (UV) exposition.

Kato et al. (1989) have shown that they can produce collagen threads cross-linked with glutaraldehyde having an UTS of 50 to $66 \mathrm{MPa}$ in wet conditions. Those results are in the same range than UTS of rat tail tendons (33 to 39 $\mathrm{MPa})$. The UTS is divided by a factor 2 for severe dehydration and for EDC treatment. As for Young modulus, they reach 400-500 $\mathrm{MPa}$ with glutaraldehyde CXL process. Zeugolis et al. (2008) evaluated mechanical properties of collagen threads hung and dried at room temperature [121]. Young modulus of those strands ranged from 1 to $3 \mathrm{GPa}$ and UTS from 0.2 to $0.3 \mathrm{GPa}$. These results have similar values as native tendon (Table 2). However, we have to keep in mind that in this case, tensile testing is performed in dry conditions, which are not close to the physiological ones. As for Kato et al. (1989), they lose on average 3 orders of magnitude in wet conditions. Finally, to have as many bonds as possible, some combinations of CXL processes can be used (dehydrothermal with cyanamide [125] etc).

The alignment of collagen fibrils inside the collagen threads is also a parameter to take into account. The extrusion technique has the main advantage to induce collagen fibrils alignment in the longitudinal axis, thanks to the high constraints applied when collagen solution is forced to pass through the narrow die ([118], [124]). This phenomenon can be further increased by stretching the threads [122].

Lai et al. (2011) observed that, in vitro, human fibroblasts cultured during 1 or 2 days have an elongated shape following the longitudinal axis of the collagen fibrils [124]. This suggests that there is some contact guidance of the cells on the collagen threads structure. Cornwell et al. (2007) highlighted the problem of CXL post-process on collagen threads. Indeed, they observed that fibroblast migration rate decreased by using CXL agents [127]. A compromise between the improvement of mechanical properties with CXL techniques and the upgrading of cell proliferation must be found. To go further, Dunn et al. (1993) implanted their collagen threads in subcutaneous space of the rabbit during 4 weeks. The threads were surrounded by a fibrous tissue and were colonized by inflammatory cells and fibroblasts [125]. Threads crosslinked with DHT combined with cyanamide were degraded over 4 weeks. Cavallaro et al. (1994) also had promising results in a canine ligament model and a rat abdominal repair model that can be transposed for tendon repair [118]. They noticed the neovascularization and the cell infiltration in the collagen threads. In both studies, no rejection of the collagen scaffolds was observed.

\subsection{Electrospinning}

Electrospinning is a widespread technique for fibrous scaffold production. This method, based on a simple and inexpensive set-up, uses an electrical field to cast various materials, such as polymer solutions or melts, into fibers, making it attractive for tissue engineering. Briefly, a high voltage is applied between a grounded target and a needle provided with the liquid of interest, leading to charge accumulation at its surface [128], [129]. For sufficiently high voltage, the surface tension is overcome, leading to the formation of a liquid jet that forms a fiber which dries and is collected on the target, resulting in a fibrous mat (Figure 5B).

To achieve electrospinning of a polymer solution, many requirements must be met. In addition to the setup parameters such as voltage or solution feeding rate, and the ambient conditions such as temperature and humidity, intrinsic characteristic of the solution are paramount to electrospin it. Ideal solutions must have low surface tension and high conductivity [130], viscous enough to form a stable jet that does not break before drying [131] but not too much to ensure sufficient flowability [132] and dry fast before reaching the collector [133]. Usual solvents such as acetic acid lack the viscoelastic properties needed to form a stable jet and do not evaporate fast enough before reaching the collector [133]. Collagen electrospinning was achieved using fluoro-alcohols such as 1,1,1,3,3,3hexafluoro-2-propanol [134]-[136] and 2,2,2trifluoroethanol [137]. However, such a process was proven to denature collagen [133], [138]. Indeed, resulting collagen is soluble in water, does not exhibit characteristic D-banding under transmission electron microscopy and has 
lower denaturation temperature. Further proofs were given thanks to circular dichroism, electrophoresis and infrared spectroscopy. Attempts succeeded in electrospinning collagen in benign solvent such as Phosphate Buffer Saline and ethanol mix [130] or acidic solution with poly(ethylene oxide) [139], [140]. Bürck et al. (2013) demonstrated that electrospun collagen fiber from this solvent did not preserve much better the native structure of collagen and that part of the denatured collagen was intrinsically due to the electrospinning process and not to the solvent [133].

Recently, Elamparithi et al. (2015) reported successful electrospinning of collagen in 97:3 acetic acid:DMSO mix with fibers exhibiting the characteristic D-banding of native collagen [141]. However, no further investigation on native collagen content was carried out. The cross-linking of the resulting fibrous mat after electrospinning with 1-ethyl-3(3dimethylaminopropyl) carbodiimide hydrochloride does not allow for water solubility test and give surprisingly low mechanical properties with modulus and tensile strength at maximum load of a few $\mathrm{kPa}$. This may be suitable for nonload bearing tissue reconstruction such as cardiac tissue, aimed by the authors, but not for tendon reconstruction.

Thus, electrospinning of collagen for tendon reconstruction seems only relevant when collagen is co-electrospun with biodegradable synthetic polymers such as poly(l-lactide-co$\varepsilon$-caprolactone) [142] or poly(L-lactic acid) [100], as it improves biocompatibility of synthetic polymers. For instance, an interesting work was published by Ladd et al. (2011) who electrospan two different polymers with collagen to reproduce the musculo-tendinous junction: the poly(L-lactic acid), being stiffer, for the tendon part and poly( $\varepsilon$-caprolactone) for the muscle part [100]. Whereas the synthetic polymers provide mechanical strength, the collagen promotes good cell viability close to $100 \%$ after 7 days of both $\mathrm{C} 2 \mathrm{C} 12$ myoblasts and NIH3T3 fibroblasts seeded on each part.

\subsection{Freeze-casting}

Freeze-casting, also called ice-templating, is a common technique to produce highly porous scaffolds from solutions or suspensions in solvents such as water or camphene. Considering a water based polymer solution, by simply freezing it, phase segregation occurs between ice crystals and a phase concentrated in polymer (Figure 6A \& B). After freezing, the sample is freeze-dried under vacuum, sublimating ice crystals (Figure 6B) and resulting in a dried polymer sponge (Figure 6C). Depending on the protocol used and the parameters chosen, such as cooling rate, final temperature or size and shape of the vessel, it is possible to favor different crystalline structures and grow ice crystals of different size, thus tuning size and shape of the pores [143].

Enabling production of highly porous and anisotropic scaffolds, ice templating of collagen seems promising to promote cell proliferation, alignment and differentiation required for tendon reconstruction. The pores usually obtained in collagen sponges, ranging from 50 to $300 \mu \mathrm{m}$, are optimal for cell culture. Switching from small to large pores can be easily done, by decreasing final temperature or cooling rate, or by crystal annealing [144].

Even though the principle of freeze-drying seems simple, the physics behind is not straightforward. Pawelec and coworkers have realized interesting observations on collagen solution freeze-casting and the dependence of pore size [145] and anisotropy [146] upon parameters. They also investigated the effect of the addition of $\mathrm{NaCl}$ and sucrose [147], and of heat transfer between the mold and the heat sink [148] on collagen freeze-casting. They took their work one step further by culturing ovine primary patellar tendon cells on freeze-casted collagen uniaxial and anisotropic sponges in a fibrin gel [149], exhibiting higher cell proliferation, metabolism and matrix production thanks to fibrin gels and a cell phenotype control by the collagen scaffold structure.
A

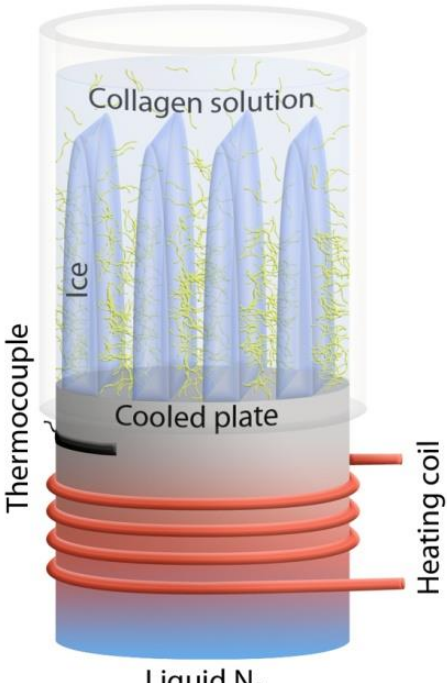

Liquid $\mathrm{N}_{2}$
B

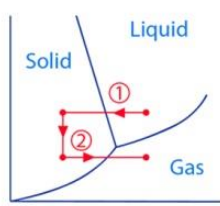

C

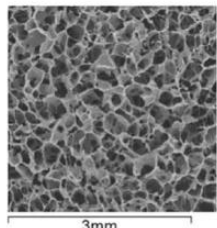

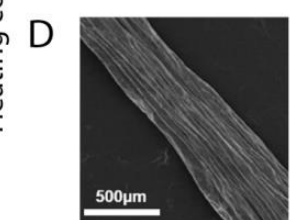

\section{Freeze-casting}

Figure 6: Freeze-casting setup schematics (A) with the paths followed on the water phase diagram (B) and a resulting collagen sponge observed under SEM $(C)$ and a pre-fibrillated collagen scaffold after freeze-casting (D). (A) Freeze-casting schematic where a collagen solution is directionally frozen on a metallic cooled plate, which other side is dipped in liquid nitrogen and which temperature is controlled thanks to a thermocouple and a heating coil; causing segregation between ice crystals and a concentrated phase in collagen. (B) Water phase diagram schematic where the path followed during freeze-casting (1) and then freeze-drying (2) is drawn. (C) An isotropic collagen sponge observed under SEM (Adapted from Davidenko et al. 2015 [150], Creative Common License). (D) SEM picture of Lowe et al.'s longitudinal scaffold, prefibrillated before freeze-casting in a high aspect ratio vessel (Adapted with permission from Lowe et al. 2016 [151]. Copyright 2016 American Chemical Society) 
Whereas Pawelec and coworkers mainly focused on the freeze-casting of the collagen itself, Caliari and coworkers rather investigated cell culture on freeze-casted scaffolds for tendon reconstruction. Using collagen mixed with glycosaminoglycan (10:1) (Coll-GAG), Caliari and Harley demonstrated that pores above $150 \mu \mathrm{m}$ were more favorable for cell proliferation and metabolism [152] while a mix of Insulin Growth Factor 1 (IGF-1) with Growth/Differentiation Factor 5 (GDF-5) was more effective to promote cell proliferation, collagen production and tendon associated structural protein gene expression [153]. Given the relatively low mechanical properties of collagen sponges (modulus around $800 \mathrm{kPa}$ in dry state), Caliari et al. (2011) made an attempt to compensate this by wrapping the freeze-casted scaffold in a collagen air dried membrane crosslinked with 1-ethyl-3-[3dimethylaminopropyl]carbodiimide hydrochloride and $\mathrm{N}$ hydroxysulfosuccinimide, resulting in a core shell scaffold with a $8 \mathrm{MPa}$ modulus, UTS between 0.3 and $0.9 \mathrm{MPa}$ and strain at break from 10 to $25 \%$ [154]. Ice templating being also promising for bone reconstruction research, they also produced a bi-component material Coll-GAG/ Calcium phosphate mineralized Coll-GAG (CaP Coll-GAG) scaffold to mimic bone-tendon junction, together with specific growth factors on each side to study the impact on mesenchymal stem cells (MSCs) [155]. Each side exhibited up-regulation of pro-osteogenic and pro-tenogenic genes in the CaP Coll-GAG and Coll GAG parts respectively.

In most articles, two points are not tackled. The first and more important one is the self-assembly of collagen, which could improve mechanical properties, cell adhesion and differentiation [113], [114]. The second one is the shape of the scaffolds that differs from tendons. Since the geometry of the vessel and its filling height highly impact the scaffold structure, any modification of the former will impact the latter. This increases the difficulty to mimic living tissues with this method. However, Lowe et al. addressed those two problems [151]. By ice-templating self-assembled collagen, they produced high aspect ratio and highly aligned porous collagen scaffolds (Figure 6D) that could be suitable for Achilles tendon for instance. Uniaxial micro features at the surface enabled rat dermal fibroblasts and chick dorsal root ganglia explants alignment. Precise pore analysis was not reported, neither cell culture inside the scaffold. It should be noted that the scaffolds were obtained without any cross-linkers, and that even though the mechanical properties of the scaffold are low (Young modulus $\sim 600 \mathrm{kPa}$, UTS $150 \mathrm{kPa}$, strain at break $110 \%$ ), they are in the same range as those obtained with cross-linked but not fibrillated scaffolds [154]. The addition of carbodiimide cross-linker could further stiffen the material.

On the way to improve mechanical strength and modulus of scaffolds, an innovative design was developed by Mozdzen et al. [156]. They freeze-casted a collagen-GAG solution into a 3D printed acrylonitrile butadiene styrene (ABS) array. Even though ABS may not be the most suitable polymer for tendon reconstruction because of its lack of biocompatibility [157], the composite design of this scaffold is of interest. It combines the mechanical strength of ABS with the high biocompatibility of collagen sponges. Comparing sinusoidal ABS fiber arrays of different amplitude to straight ABS fiber arrays, they were able to tune elastic properties of the scaffold in a crimp-like fashion. This gives a glimpse of the promises held by 3D printing for tissue reconstruction.

\subsection{D printing}

3D printing, or additive manufacturing, has breached in most good manufacturing sectors in the last few years and tissue reconstruction is no exception. Based on the knowledge acquired on scaffold manufacturing and facing new intrinsic problems, it gives high hopes for its capacity to design complex macroscopic shapes of scaffolds as seen in the previous paragraph, as well as enable precise cell deposition. It consists in a layer-by-layer computer aided deposition that enables the construction of $3 \mathrm{D}$ structure designed on the computer.

This technique is currently used in research on skin, cartilage, bone, aortic valve [158]. Different methods of deposition have been developed such as inkjet, extrusion (Figure 7A left) or laser-assisted bioprinting [158]-[160], as well as different hydrogel based inks, called bio-inks [115]. The use of collagen as an ink for 3D printing raises an obvious interest and is investigated especially for bone [161]-[163] and cartilaginous tissue reconstruction [164], [165]. However, current research face difficulties to obtain self-standing 3D printed structures. Thus, collagen is often used to enhance the bioactivity of widespread bioinks such as alginate [166], [167] or agarose [162] that are cheap and easy to use but show lower bioactivity compared to main components of the ECM. It is also used with calcium phosphate [161] for bone reconstruction or mixed with fibrinogen [168] that is easy to crosslink.

Other techniques to print collagen self-standing structures are the deposition of collagen on a cold plate to freeze the solution when deposed [169], [170], or the use of sacrificial negative molds [171], [172]. An original process that is worth mentioning is the printing of a core-sheath collagenalginate structure [173].

Here again, collagen is sometimes used without inducing fibrillogenesis. Besides, the protocols used can be too harsh to incorporate cells in the bio-ink, preventing the use of additive manufacturing to deposit cells in an accurate and homogeneous way. A few articles deal with pure collagen self-assembled during or after printing [164], [174]. However, for collagen [174] as well as for fibrinogen [168], this leads to tedious protocols where the scaffold is incubated, after each layer printing, either at $37^{\circ} \mathrm{C}$ or with thrombin respectively. 

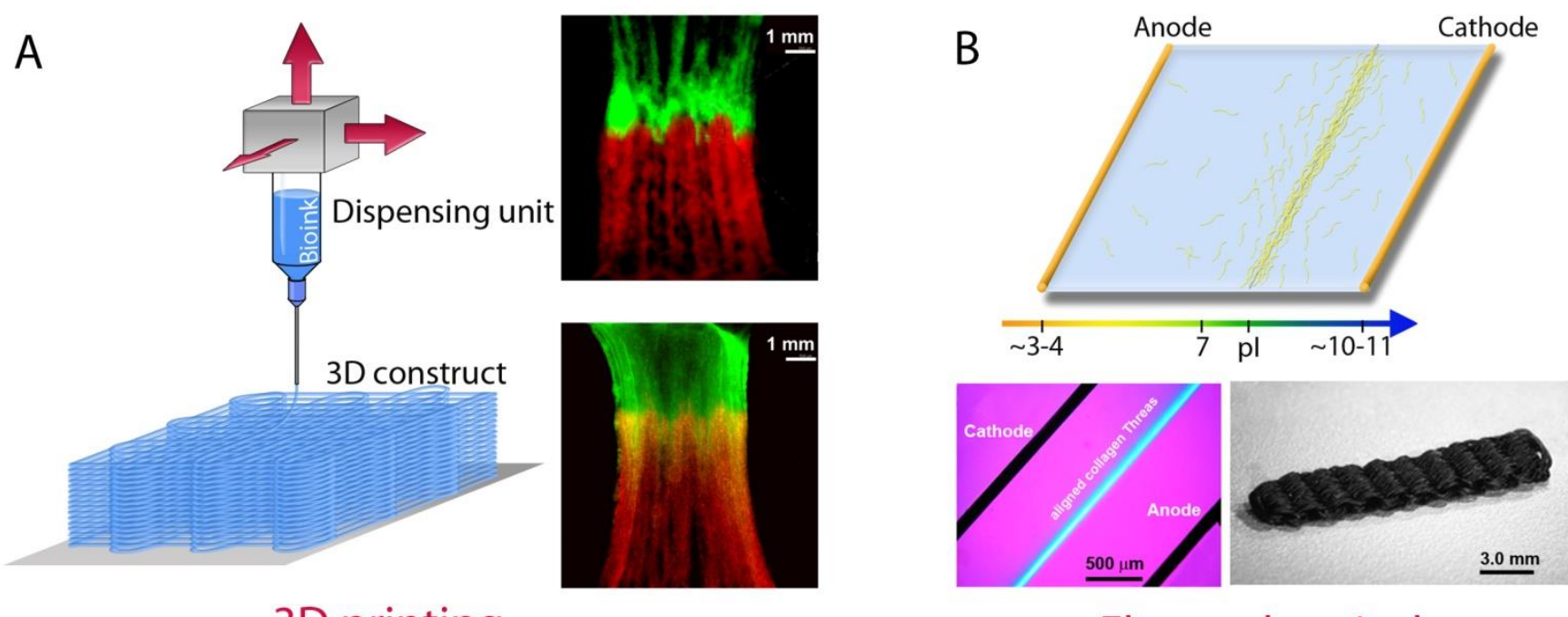

\section{D printing}

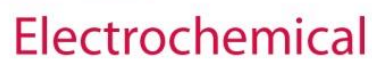

Figure 7: Schematics and resulting scaffolds of extrusion 3D printing and electrochemical techniques (B). (A) Left: schematic of 3D printing setup where a dispensing unit is monitored in the three directions of space by a computer to deposit bio-ink layer by layer. Top right: 3D printed scaffold to reproduce myo-tendinous junction, accurately seeded with DiO-labeled C2C12 myoblasts (green - top) and DiI-labeled NIH/3T3 fibroblasts (red - bottom) after 1 day in culture. Bottom right: Same scaffold after 7 days in culture exhibiting the interface region in yellow. (B) Top: schematic of the electrochemical technique where a voltage is applied to a collagen solution between the anode and the cathode, creating a $\mathrm{pH}$ gradient and inducing collagen migration to the isoeletric point $(\mathrm{pI})$ region and alignment of the molecules. Bottom left: picture of a thread of electrochemically aligned collagen (ELAC) between the two electrodes observed with polarized microscopy. Bottom right: picture of a scaffold woven from triple ELAC threads twisted together. (A, top and bottom right) adapted with permission from Merceron et al. (2015) [176]. (B, bottom) adapted with permission from Younesi et al. (2015) [179].

One currently adopted strategy is the printing side-by-side of an artificial biodegradable polymers and a bio-ink with incorporated cells. The artificial polymer confers mechanical integrity to the scaffold whereas the bio-ink allows exact cell deposition with suitable bioactivity [168], [175]. To our knowledge, despite the control on porosity, macroscopic structure and cell incorporation that this technique offers, no article about 3D printing of collagen for tendon reconstruction has been published yet. This can be explained by the difficulty of handling collagen and the poor mechanical properties obtained with collagen in other domains such as extrusion. As collagen is often used with other bio-inks for its bioactivity, some chose gelatin instead for its lower price. For instance, Merceron et al. (2005) published the co-printing of two synthetic polymers polyurethane (PU) and poly( $\varepsilon$-caprolactone) (PCL) together with a bio-ink based on hyaluronic acid, fibrinogen and gelatin, to reproduce the musculo-tendinous junction [176]. The bio-ink contained $\mathrm{C} 2 \mathrm{C} 12$ myoblasts on the PU side while the bio-ink on the stiffer PCL side contained NIH/3T3 (Figure 7A top right). The construct exhibited good cell viability (Figure 7A bottom right), high cell alignment and characteristic musculo-tendinous gene upregulation. They highlighted the ability offered by 3D printing to deposit different cell types in precise locations, paving the way to complex multicellular scaffolds for regeneration.

\subsection{Electrochemical techniques}

Applying an electric field to a collagen I monomer solution enables to control the spatial aggregation of molecules, resulting in collagen membranes [177] or bundles measuring 50 to $400 \mu \mathrm{m}$ in diameter and several centimeters in length [178]. Electrochemical reactions primarily due to the electrolysis of water create a $\mathrm{pH}$ gradient. In the $\mathrm{pH}$ region corresponding to the isoelectric point, the collagen becomes less sensitive to the electric field and stops migrating due to global neutral charge (Figure 7B top and bottom left, [179]). In these biomimetic constructs small fibers are highly oriented along the bundle axis, increasing the mechanical properties as compared to randomly oriented controls, and inducing an alignment of tendon derived fibroblasts that migrate into braided bundles [178]. Isoelectric focusing technology was further adapted to enhance directional neuronal growth [180]. This study also unraveled the underlying hierarchical structure, with nanofibrils aggregating into $\sim 500 \mathrm{~nm}$ diameter D-banded fibrils that align to form fibrils. The influence of phosphate buffer and incubation time on strength and D-banding pattern of the electrochemically aligned collagen (ELAC) threads was also studied and advocated PBS $1 \mathrm{X}$ during $12 \mathrm{~h}$ as the optimal fibrillation buffer [181]. After 96h incubation, Young modulus could attain $6 \mathrm{MPa}$ in wet conditions. The ability to induce tenogenic differentiation of human MSCs was evidenced on the threads with the increase of tendon specific markers such as scleraxis and 
tenomodulin [182]. An in vivo study was led to assess the response of rabbit patellar tendon (PT) to braided ELAC threads [183]. Four months post-implantation, crosssectional area, mechanical properties and tendon-fascicles content of the PTs treated with ELAC were optimized as compared to controls, but these differences were not evident anymore after 8 months. A low-grade granulomatous inflammation was observed at 4 months but it spontaneously diminished between 4 and 8 months. Different crosslinking strategies were investigated to improve the mechanical properties of ELAC threads, and the increase of genipin concentration in conjunction with highly concentrated ethanol was advocated [184]. Further processing was made with the fabrication of collagen textiles (Figure $7 \mathrm{~B}$ bottom right) by weaving ELAC triple threads after twisting continuous ELAC threads obtained with a kinematically rotating linear electrode pair [185]. MSCs seeded in the porous scaffolds underwent tenogenic differentiation, and the mechanical properties reproduced some aspects of the functional mechanics of native tendon, in particular comparable load-displacement curves in the linear regions. Computer aided design that helped produce patterned electrodes enabled to obtain highly porous collagen scaffolds with controlled geometries that can be further combined to form layered structures [186]. The elastic modulus of these different types of constructs ranged from 5-40 $\mathrm{MPa}$.

\subsection{Cell-mediated collagen gel compaction}

Cells embedded in loose collagen hydrogels have the ability to compact them into denser tridimensional constructs. This cell-mediated collagen gel contraction was first reported in 1979 by Bell and coworkers [187]. Among the first investigators studying this phenomenon, Stopak and Harris showed that it stems from cell contractility [188]. They also embedded fibroblastic cell explants in collagen gels and observed both fiber alignment and cell orientation along the axis between the explants. They carried out other experiments in which fibroblasts, initially dispersed within a gel, could contract the matrix between fixed posts (Figure 8A).

This resulted in complex patterns of crisscrossing strands. In order to explain the reorientation of the different components of cellularized gels Barocas and Tranquillo proposed in 1997 a mathematical model in which fibril alignment results from traction forces exerted by the cells under anisotropic conditions, such as a mechanical constraint or inhomogeneous cell distribution. According to this model, cells then align along the fibrils by contact guidance [189]. Huang et al. (1993) showed an increase in stiffness over time of fibroblast-populated collagen constructs between fixed posts, and demonstrated that lysyl-oxidase crosslinking activity was necessary for this mechanical enhancement [190]. Autologous bone derived MSCs were further used for Achilles tendon repair in rabbits [191]. In these experiments Young et al. (1998) used a cell-gel composite contracted onto a pre-tensioned

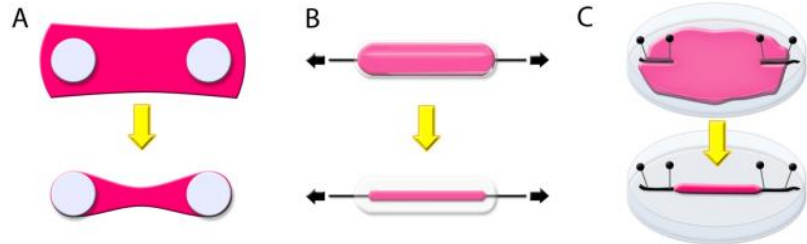

Figure 8: Schemes of various types of tendon constructs based on cell-mediated gel compaction. On these topviews cell-gel mixtures are depicted pink, and the contraction process is represented over time, from top to bottom. (A): Principle of collagen matrix contraction between fixed posts, depicted white, as introduced in [186] and further developed in [187], where cells and collagen gels are first pipetted into wells. The cells contract the gels around two posts located at the base of each well. (B): Collagen gel-cell composite contracted onto a pre-tensioned suture, as introduced in [188]. Each construct was created in a glass trough, which contained a tensioned suture (horizontal arrows). (C): Tendon construct formation between pinned sutures, in the presence of cells only [189], fibrin-cell mixture [190], or collagen-cell mixture [191].

suture (Figure 8B). They showed that the mechanical properties were greatly enhanced 12 weeks after implantation in 1-cm-long gastrocnemius tendon gaps compared to controls implanted with suture material only. MSC-collagen composites, implanted into central patellar tendon defects of rabbits, showed a significant improvement of the biomechanical properties as compared to natural repairs, with cells remaining within the repair site [192], [193]. No additional benefit of increasing cell density, from 1 to 8 million per $\mathrm{ml}$, was observed. Formation of ectopic bone in $28 \%$ of the composite grafted repairs was noticed. Lowering the cell to collagen ratio in a different system, where the MSCs were placed into silicon dishes between fixed posts 2 weeks prior to implantation (Figure 8A), showed no significant difference in material and histological properties between implants with 40,000 cells/mg collagen or 80,000 cells/mg collagen twelve weeks after surgery [194]. There was also no significant difference in mechanical properties between these implants and acellular ones, with an average modulus reaching $20 \%$ of normal patellar tendons.

Scaffold-free constructs were also obtained by selfassembly of collagen and non-collagenous molecules produced by rat Achilles tendon cells grown to confluence between two pinned sutures, serving as anchor points, for 2 weeks [195] (Figure 8C). The obtained cylinders presented a tangent modulus of $17 \mathrm{MPa}$, as compared to $27 \mathrm{MPa}$ for embryonic chicken extensor tendons. Tendon-skeletal muscle constructs were also engineered in vitro in scaffoldfree environment, with the reconstitution of myo-tendinous junctions either by co-culturing fibroblasts and myoblasts between fixed posts [196] or by pinning tendon constructs on muscle cell monolayer [197]. Fibrin has also been used as a material for tendon engineered constructs. Kapacee et al. showed that in fixed length fibrin gels made with tendon 
embryonic cells, fibrin was replaced by aligned collagen fibrils within 6 days [198]. Similar tendon constructs were also used to investigate the role of transcription factor EGR1 towards tendon differentiation by means of forced Egrl expression programmed MSCs in a fibrin gel [199]. Neal et al. (2014) developed a method using a PDMS mold and a second sacrificial mold, made of gelatin, and placed inside, to produce thin fascicle-like constructs, $\sim 100 \mu \mathrm{m}$ in diameter, of fibrin hydrogel with cells embedded in it [200]. This strategy enabled to combine molding and cellmediated gel compaction of the freely suspended hydrogel anchored to the PDMS walls. C2C12 mouse myoblasts alignment and maturation were promoted. According to preliminary work, the method could also be extended to 3T3 fibroblasts and horse tenocytes. More recent studies, led by two different groups, showed that fibrin gels enhance the properties of tendon-engineered constructs over collagen-based materials. Yeung et al. (2015) led a comprehensive study of chick tendon fibroblast transcriptomes inside gels between pinned sutures and showed that fibrin-based constructs recapitulated more closely gene expression that occurs during tendon development as compared with collagen-based ones [201]. Cell-synthesized collagen matrix also exhibited better fibrils alignment in the fibrin-based gels. Breidenbach $e t$ al. (2014) showed that for approximately 14 days in cell-gel mixtures between posts embryo tendon/ligament progenitor cells exhibited enhanced tenogenic expression, collagen alignment and linear modulus with fibrin [202]. Still, a reduction in mechanical, biological and mechanical properties was observed in fibrin constructs submitted to cyclic stretching $(2.4 \%$ strain, $1 \mathrm{~Hz}, 3000$ cycles/day) whereas this was benefic to collagen constructs. The main conclusion is that the various parameters of mechanical stimulation must be fine-tuned for each type of construct.

\subsection{Other promising methods}

In this section we will describe some other methods, which have been applied to the generation of a high anisotropy inside collagen solutions. They often rely on the combination of multiple physical phenomena, and adapted for a better processability they may be promising candidates to generate biomaterials for tendon repair.

\section{$\underline{\text { Magnetic alignment }}$}

Torbet and Ronzière were the first to propose the magnetic alignment of collagen during self-assembly in solutions at low concentration [203]. They used magnetic field strengths between 1.9 and 5.6 T. Aligned fibrils being in the same plane as the field, they inferred the additional ordering effects of surface interactions. Guido and Tranquillo further showed that fibril orientation could be controlled by independently varying the magnetic field strength or temperature during fibrillogenesis, pointing out the possible orienting effect of the magnetic field acting over an extended fibrillogenesis period due to a lower temperature [204]. When human foreskin fibroblasts are cultured in the gel, their orientation correlates with that of the fibrils. Chen et al. (2011) showed that, in tilapia fishscale collagen solutions, fibril alignment can also be induced after fibrillogenesis with magnetic fields of 6 or 12 $\mathrm{T}$ [205]. The rheological properties obtained were similar in both cases, with either non-prefibrillated or fibrillated and crosslinked collagen prior to magnetic treatment, with higher values than those of un-oriented gels. Those properties were dependent on strength and application time of the magnetic treatment. In both cases, collagen fibrils maintained a typical D-periodic structure of $60-70 \mathrm{~nm}$. Guo and Kaufman (2007) showed that it was also possible to obtain fibril alignment with a small magnet by combining flow and magnetic field effect [206]. Surface modified paramagnetic iron oxide beads placed inside collagen solutions induce collagen alignment within areas of hundreds of square microns, the domains being larger when timescales of gelation and bead motion to the magnet poles are similar. Multiple layers of collagen are obtained. C6 glioma cells embedded in the matrix were able to remodel it by bundling the fibers.

\section{$\underline{\text { Microfluidic alignment }}$}

Lee et al. (2006) proposed the microfluidic alignment of collagen fibrils in dilute solutions under flow, and the orientation obtained appeared to be particularly efficient within PDMS microchannels 10 to $100 \mu \mathrm{m}$ wide [207]. They inferred that the rapid attachment of fiber precursors along the channel walls and the subsequent influence on new fiber growth were involved, but mentioned that no firm conclusion could be drawn from their experiments to provide an explanation. Aortic bovine endothelial cells grown on the UV-crosslinked collagen matrix aligned along the direction of the fibers. Saeidi et al. (2009) studied the formation of fibrils on glass surface under the influence of flow between two plates [208]. The height of the microchamber could be changed which enabled to vary the shear rate at the walls. In this context self-assembly process is influenced by shear rate, as well as self-assembly energetics and surface energy. Moderately aligned collagen fibrils were obtained. They result from the aggregation of 3-5 $\mathrm{nm}$ microfibrils and present no D-banding, possibly due to the distortion of the fibrillar structure by the surface energy of the glass. The best alignment was observed at shear rates between 20 and $80 \mathrm{~s}^{-1}$, and above these values the fibrils would often turn down-stream due to instabilities. Surface bound aligned collagen I matrices were produced on copolymer-coated or glass substrates thanks to a microfluidic system [209]. Collagen deposited under flow was either pre-fibrillated or not. The morphology of the matrices obtained could be controlled. Fibril coverage was directly dependent on collagen concentration, with extended matrices at $0.8 \mathrm{mg} / \mathrm{ml}$ as compared to 0.2 and $0.4 \mathrm{mg} / \mathrm{ml}$. The flow rate also had a direct impact on the alignment of pre-fibrillated collagen, with highest alignment degree at $11 \mu \mathrm{l} / \mathrm{min}$ as compared to 4 and $0.45 \mu \mathrm{l} / \mathrm{min}$. A slight decrease of alignment was seen on more hydrophilic surfaces. Pre-conditioning of nonfibrillated collagen $(0.8 \mathrm{mg} / \mathrm{ml})$ in heated tubing before 
entering the channel had a direct impact on the fibers obtained, which are longer and more individual after 30 minutes as compared to 5 and 10 minutes.

Recently Haynl et al. (2016) used a microfluidic chip connected to three syringes to produce collagen microfibers upon an increase in the $\mathrm{pH}$ and the presence of PEG [210]. The diameters of the fibers can be varied depending on the extrusion buffer and the flow rates. With a collagen flow rate of $50 \mu \mathrm{h} \mathrm{h}^{-1}$ and buffer flow rates in between 235 and $550 \mu \mathrm{h} \mathrm{h}^{-1}$ the fibers could be collected using a rotating spool. The diameters obtained under these conditions are around $10 \mu \mathrm{m}$ and after air-drying from 3 to $6 \mu \mathrm{m}$. Alignment of the fibrils within the microfibers was evidenced by scanning electron microscopy and polarized FTIR spectroscopy. Young moduli obtained were $4138+$ +/$512 \mathrm{MPa}$ after drying. Neuronal cells cultured on the microfibers aligned along the longitudinal axes.

\section{$\underline{\text { Rotary shearing }}$}

Yunoki et al. (2015) produced thick collagen gel bundles with aligned fibrils by means of rotary shearing to a dense collagen solution $(1.8 \%)$, with gelation triggered upon rotation [211]. Well-aligned fibrils, as evidenced by scanning electron microscopy and birefringence measurements, were observed in the marginal regions of 1 $3 \mathrm{~mm}$ thick disc-shaped gels. The optimal shear-rates for fibrils alignment were between 2-5 $\mathrm{s}^{-1}$. Rectangles and dumb-bell-shaped specimens cut from the discs $\left(7^{*} 12 \mathrm{~mm}\right.$ and $4 * 16 \mathrm{~mm}$ respectively) in the direction of the rotation had Young modulus of $180 \mathrm{kPa}$ after crosslinking with genipin, as compared to $30 \mathrm{kPa}$ for the rectangles perpendicular to the rotation. After EDC/NHS crosslinking the values reached were 280 and $130 \mathrm{kPa}$, respectively. 3T3 cultured on aligned matrices were spindle-shaped in the fibril alignment direction.

\section{Imprinting}

An innovative technique was invented by Tong et al. to study the role played by the biophysical and biochemical environment, as well as mechanical properties, on MSCs differentiation into tenocytes [102]. They replicated tendon structure by imprinting longitudinal sections of bovine Achilles tendons with PDMS, making a negative then a positive replica reaching sub-micron precision (Figure 9).

By changing monomer concentration, they were able to tune the elastic modulus of the imprint from 0.35 to 3.5MPa. They demonstrated that surface topography, collagen coating, and stiffness were paramount to promote MSCs differentiation. In addition to such valuable information, this technique could be used to mold scaffold for tendon reconstruction, resulting in optimal surface topography.

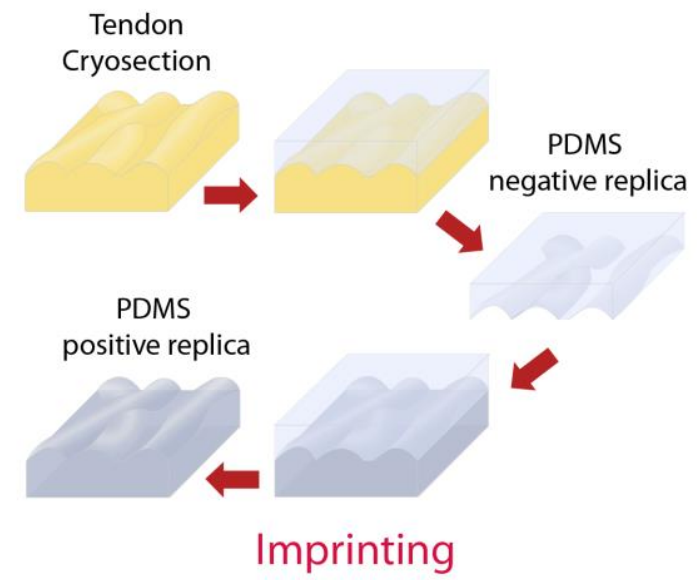

Figure 9: Schematics of the imprinting technique. A PDMS negative replica of a longitudinal tendon cryosection is made to produce a subsequent PDMS positive replica.

\section{Fiber drawing}

Another interesting, yet simple technique, has been reported by Paten et al. (2016) [212]. They were able to draw centimeter-long collagen fibers with a diameter around $50 \mu \mathrm{m}$, just by poking a collagen solution drop left a few minutes under dry nitrogen atmosphere with a glass micro-needle (Figure 10). The flow-induced crystallized fibers presented outstanding aligned structure on the outer shell. Fibers were stable when kept under strain or in polyethylene glycol solution. This could help understanding tendon morphogenesis and, above all, by weaving such fibers, it could provide a promising and simple scaffold production, with inherent high porosity and alignment to promote cell proliferation and differentiation.

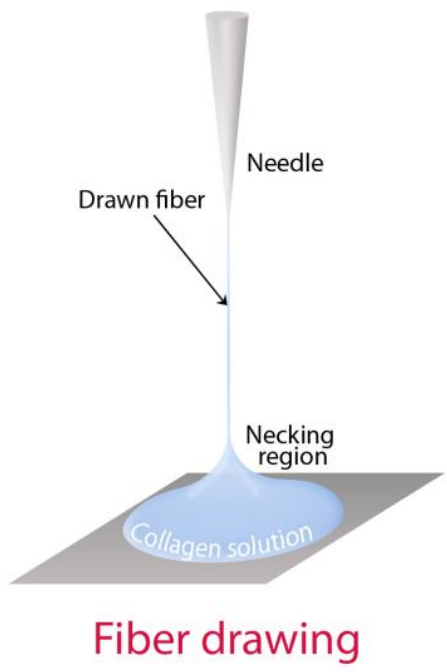

Figure 10: Schematics of the fiber drawing technique. A glass micro-needle is used to poke the surface of a collagen solution left 150 s to concentrate under nitrogen atmosphere, and draw a fiber. 


\section{$\underline{\text { Plastic compression and gel aspiration-ejection }}$}

Plastic compression is a cell-free, controlled process first introduced by Brown et al. [213], to produce dense, cellular, mechanically strong native collagen structures. This technique relies on external mechanical loading and capillary fluid flow to expel interstitial liquid. The cell viability is high during and after compression of cellular collagen gels, even surpassing highly hydrated collagen gel counterparts, with an increase in proliferation over time [214]. Plastic-compressed collagen gels seeded or not with rabbit flexor tendon cells, $20-40 \mu \mathrm{m}$ thick, were rolled in order to produce spiral rolls $22 \mathrm{~mm}$ in length $\mathrm{x} 2.25 \mathrm{~mm}$ in diameter [215]. These rolls were placed in a test site across intercostal spaces in rabbits to provide tensile cyclic loading in vivo for 5 weeks. Collagen remodeling and tensile mechanical strength were enhanced in the cellseeded gels. Gel aspiration-ejection (GAE) technique was further developed to produce anisotropic, cell-seeded, injectable collagen, without the use of crosslinking [216]. After incubation of low concentrated collagen solutions the resulting gels are aspirated into capillaries by means of a negative pressure applied with a syringe. Fibril alignment was evidenced by scanning electron microscopy and polarized ATR-FTIR spectra. 3T3-seeded collagen gels submitted to GAE showed a rapid orientation of the cells along the direction of the fibrils within one day. Constructs obtained through this process and exposed to the appropriate supplements also accelerated the differentiation of seeded murine MSCs towards osteoblastic and neuronal lineage, as compared to plastic-compressed cell-seeded constructs.

\section{DETERMINANT IMPACT OF MECHANICAL STIMULATION}

Tendon development, homeostasis and healing are influenced by their loading environment [2]. During rehabilitation, a fine balance between complete immobilization and loading is necessary to improve ECM production and tendon repair [217]. Before implantation, engineered constructs can be exposed to static and dynamic loads in order to better mimic the in vivo conditions and potentially improve their properties. The results obtained may also give insights into the influence of mechanical stimulation on cell differentiation, activity and on biomechanical enhancement (Table 3).

The influence of uniaxial loads on ECM components was studied using collagen constructs without cells. Static stretching of self-assembled collagen fibers extruded in phosphate buffer, then air dried and rehydrated, induced a modulus increase from $1.82 \mathrm{MPa}$ with $0 \%$ stretch to 45 $\mathrm{MPa}$ after $50 \%$ stretch, measured after air drying [218]. Increased collagen fibril orientation was supposedly involved based on birefringence values. Static stretching of PDMS substrates coated with a multilayer film composed of collagen and alginate enabled to produce surfaces with aligned collagen fibrils, that were further stabilized with genipin crosslinking, with an optimal strain of $100 \%$ for alignment [219]. Cyclic loading of strips of collagen gels obtained by plastic compression promoted fibril fusion as evidenced by transmission electron microscopy [220]. Tensile tests showed a modulus increase from $244 \mathrm{kPa}$ after 1 cycle to $535 \mathrm{kPa}$ after 144 cycles, with $20 \%$ maximum strain for each cycle. There was also an increase in break strain and a 4.5 fold rise in break stress. Regarding the mechanical stimulation of cells alone, a cyclic axial strain applied on human tendon fibroblasts showed a strong influence on cell proliferation, highlighting the need to fine-tune the stretch [221].

Continuous cyclic strain inhibited proliferation of four types of cells including rabbit flexor tendon derived cells, whereas an intermittent cyclic strain could enhance cell proliferation in adipoderived stem cells and sheath fibroblasts [222]. Rat bone marrow MSCs submitted to an uniaxial cyclic stretching of $10 \%$ at $1 \mathrm{~Hz}$ for durations ranging from 3 to $36 \mathrm{~h}$ showed an increased expression of collagen types I and III and of tenascin-C [223]. The percentage of cells oriented along or close to the stretch axis was decreased, as previously noticed with ligament fibroblasts [103] as well as with epitenon tenocytes [222]. The reorientation of the different components of cellularized gels under mechanical stimulation thus appears complex.

Garvin et al. imposed a uniaxial strain on bioartificial tendons made of avian flexor tendon cells in a collagen gel, with an elongation pattern of $1 \%$ at $1 \mathrm{~Hz}$ for one hour each day [224]. Results obtained in the first week of culture showed an alignment of the cells along the direction of strain and a nearly 3-fold increase in ultimate tensile strength as compared to the non-loaded constructs. Human bone-marrow derived MSCs in a collagen gel were also submitted to a similar stimulation protocol for 30 minutes each day [225].

Expression of scleraxis, the main tendon marker during vertebrate development, was up-regulated in the 3D constructs as compared to 2D culture, but this was maintained over time only in the constructs submitted to cyclic loading. The observed tendinous neo-tissue development could be associated with matrix remodeling activity, in agreement with the noticed modulation of matrix metalloproteinases expression. Another study led by Scott et al. (2011) with multipotent mesenchymal cell line C3H10T1/2 in the same 3D model optimized the protocol of stimulation based on the expression of scleraxis and type I collagen [226]. The insertion of a $10 \mathrm{~s}$ resting period between each repetition of stretching cycle (10\% strain, 0.1 $\mathrm{Hz}$ ) appeared to be a critical parameter.

Mechanical stimulation of another type of scaffold based on collagen type I sponge, with rabbit bone marrow MSCs applied on it, was also investigated prior and after surgical implantation into patellar tendon central third defects [227], [228]. When the peak strain was $2.4 \%$, applied every 5 
minutes for 8 hours each day for two weeks, the stimulated constructs had 4 times the linear modulus and 2.5 times the linear stiffness of their non-stimulated counterparts in vitro [228].

This was associated with increased expressions of collagen type I and type III. Repair tissues formed with constructs stimulated 2 weeks with $4 \%$ strain prior to implantation showed improved biomechanical properties twelve weeks after surgery, the maximal force being $70 \%$ of the one sustained by normal tendons, versus $55 \%$ with nonstimulated constructs [227]. The stimulated constructs also presented a 2.5 rise in linear stiffness in vitro prior to implantation. The stimulation protocol was further optimized, and peak strain appeared to be a more important parameter than cycle number and cycle repetition to

\begin{tabular}{|c|c|c|c|c|}
\hline Scaffold & Cells & Stimulation & Main results & Refs \\
\hline Collagen thread & & $\begin{array}{l}\text { Static axial strain } \\
\text { for } 24 \mathrm{~h}\end{array}$ & $\begin{array}{l}\text { Elastic modulus: } 45 \mathrm{MPa} \text { after } 50 \% \text { stretch } / 1.82 \text { for the } \\
\text { controls (air-dried). } \\
\text { Increased axial fibril orientation (birefringence) }\end{array}$ & [Pins 1997] \\
\hline $\begin{array}{l}\text { Strips of collagen gels } \\
\text { obtained by plastic } \\
\text { compression }\end{array}$ & & $\begin{array}{l}\text { Cyclic loading } \\
20 \% \text { strain maintained } 5 \mathrm{~min} \\
\text { for each cycle ( } 20 \text { min total) }\end{array}$ & $\begin{array}{l}\text { Elastic modulus: } 535 \mathrm{kPa} \text { after } 144 \mathrm{cycles} / 244 \mathrm{kPa} \text { after } 1 \\
\text { cycle. } \\
\text { UTS : } 4.5 \text { folds increase }\end{array}$ & $\begin{array}{l}\text { [Cheema } \\
\text { 2007] }\end{array}$ \\
\hline \multirow[t]{4}{*}{$\begin{array}{l}\text { PDMS substrate coated with } \\
\text { multiple layers of } \\
\text { collagen/alginate }\end{array}$} & & Static stretching & $\begin{array}{l}\text { Fiber alignment in the stretching direction with optimal } \\
\text { strain of } 100 \% \text {. } \\
\text { Cell alignment with the fibrils }\end{array}$ & $\begin{array}{l}\text { [Chaubaro } \\
\text { ux 2015] }\end{array}$ \\
\hline & \multirow{2}{*}{$\begin{array}{l}\text { Rabbit flexor tendon derived } \\
\text { cells } \\
\text { /Adipoderived stem cells, } \\
\text { /Bone marrow derived stem } \\
\text { cells }\end{array}$} & $\begin{array}{l}\text { Continuous cyclic strain } \\
8 \%-1 \mathrm{~Hz}\end{array}$ & Proliferation inhibited & \multirow[t]{2}{*}{$\begin{array}{l}\text { [Riboh } \\
\text { 2008] }\end{array}$} \\
\hline & & $\begin{array}{l}\text { Intermittent cyclic strain } \\
4 \%-0.1 \mathrm{~Hz} \\
\text { On/off : } 1 \mathrm{~h} / 2 \mathrm{~h} \text { or } 1 \mathrm{~h} / 5 \mathrm{~h}\end{array}$ & $\begin{array}{l}\text { Enhanced proliferation and collagen expression. } \\
\text { Cells perpendicular to the strain axis }\end{array}$ & \\
\hline & Rat bone marrow MSCS & $\begin{array}{l}\text { Uniaxial cyclic stretching } \\
10 \%-1 \mathrm{~Hz} \\
\text { Duration : } 3 \text { to } 36 \mathrm{~h}\end{array}$ & $\begin{array}{l}\text { Increased expression of collagens type I and III and } \\
\text { tenascin-C. Cell reorientation with less cells along the } \\
\text { stretch axis }\end{array}$ & $\begin{array}{l}\text { [Zhang } \\
\text { 2008] }\end{array}$ \\
\hline Collagen gel & Avian flexor tendon cells & $\begin{array}{l}1 \%-1 \mathrm{~Hz} \\
1 \mathrm{~h} / \text { day }\end{array}$ & $\begin{array}{l}\text { Alignment of the cells along the direction of strain. } \\
\text { UTS : } 3 \text { folds increase compared to control }\end{array}$ & $\begin{array}{l}\text { [Garvin } \\
2003]\end{array}$ \\
\hline Collagen gel & Human bone marrow MSCs & $\begin{array}{l}1 \%-1 \mathrm{~Hz} \\
30 \mathrm{~min} / \mathrm{day}\end{array}$ & $\begin{array}{l}\text { Scleraxis up-regulation maintained with cyclic loading } \\
\text { Regulation of matrix metalloproteinases expression }\end{array}$ & [Kuo 2008] \\
\hline Collagen gel & $\begin{array}{l}\text { Mesenchymal cell line } \\
\text { C3H10T1/2 }\end{array}$ & Variable strain $-0.1 \mathrm{~Hz}$ & $\begin{array}{l}\text { Increased expression of scleraxis and collagen type I with } \\
10 \% \text { strain. } \\
\text { Further increase when a } 10 \text { s resting period is inserted } \\
\text { between each cycle repetition }\end{array}$ & $\begin{array}{l}{[S \operatorname{cott}} \\
2011]\end{array}$ \\
\hline Collagen sponge & Rabbit bone marrow MSCs & $\begin{array}{l}4 \%-1 \mathrm{~Hz} \\
\text { cycle every } 5 \mathrm{~min} \\
8 \mathrm{~h} / \text { day }\end{array}$ & $\begin{array}{l}12 \text { weeks after in vivo implantation into patellar tendon } \\
\text { central third defects: maximal forces sustained are } 70 \% \text { of } \\
\text { normal tendons } / 55 \% \text { for non-stimulated constructs } \\
\text { Peak strain appears as the most critical parameter }\end{array}$ & $\begin{array}{l}\text { [Juncosa- } \\
\text { Melvin } \\
\text { 2006] }\end{array}$ \\
\hline Collagen sponge & Rabbit bone marrow MSCs & $\begin{array}{l}2.4 \%-1 \mathrm{~Hz} \\
\text { cycle every } 5 \mathrm{~min}-8 \mathrm{~h} / \text { day }\end{array}$ & $\begin{array}{l}\text { 4-fold rise in linear modulus } \\
2.5 \text {-fold rise in linear stiffness Increased expressions of } \\
\text { collagen type I and type III }\end{array}$ & $\begin{array}{l}\text { [Juncosa- } \\
\text { Melvin } \\
\text { 2007] }\end{array}$ \\
\hline Collagen sponge & Rabbit bone marrow MSCs & $\begin{array}{l}\text { Variable strain }-0.1 \mathrm{~Hz} \\
\text { Variable cycle number and } \\
\text { cycle repetition }\end{array}$ & $\begin{array}{l}\text { Constructs stimulated with } 2.4 \% \text { strain, } 3000 \text { cycles/day, } \\
\text { and one cycle repetition produced the } \\
\text { stiffest constructs, peak strain appearing as the most } \\
\text { critical parameter }\end{array}$ & $\begin{array}{l}\text { [Nirmalana } \\
\text { ndhan } \\
\text { 2008] }\end{array}$ \\
\hline $\begin{array}{l}\text { Collagen gel } \\
\text { combined with collagen } \\
\text { sponge }\end{array}$ & Rabbit MSCs & $\begin{array}{l}2.4 \%-1 \mathrm{~Hz} \\
\text { cycle every } 5 \mathrm{~min}-8 \mathrm{~h} / \text { day }\end{array}$ & $\begin{array}{l}12 \text { weeks after in vivo implantation into patellar tendon } \\
\text { central third defects: enhanced mechanical properties in } \\
\text { the repair tissue obtained with stimulated constructs }\end{array}$ & $\begin{array}{l}\text { [Shearn } \\
\text { 2007] }\end{array}$ \\
\hline
\end{tabular}

Table 3: Mechanical stimulation protocols and main results reported for cells alone, collagen constructs, and mixtures of cells and collagen. 


\section{CONCLUDING REMARKS AND PERSPECTIVES}

In the present review we have seen how current tendon repair methods are mainly based on sutures and grafts that have proved to be effective while still exhibiting intrinsic drawbacks. We have seen that, even though tendon structure is not completely understood, tendon regeneration based on bioengineered scaffolds is promising. Among the different routes available, we focused on collagen-based scaffolds, as collagen I stands out from other biomolecules as being the main structural component of tendon, as well as for its suitable biocompatibility. The diversity of techniques and the increasing know-how in scaffold design allows tackling new exciting aspects such as alignment, multi-scale organization, scaffold tailoring or multi-cell deposition.

However, mechanical properties of collagen scaffolds still remain an issue while some other artificial materials compete or even overtake tendons'. Still, several authors report that, while cross-linking improves mechanical properties and resistance to degradation, it may also damage collagen or decrease its biocompatibility. A fine balance must then be found. Cross-linking methods can be classified into two categories: chemical and physical cross-linking. Among chemical cross-linkers, widespread glutaraldehyde was proven to be cytotoxic [116]. EDC, that exhibits significant increase in mechanical properties may also decrease biocompatibility and collagen I production by cells [120]. More biological cross-linking methods such as lysyl-oxydation or glycation may be used [116]. Physical cross-linking can be achieved thanks to UV irradiation or dehydrothermal process. In some preclinical studies, the moderate mechanical properties of uncrosslinked collagen scaffolds have been shown to increase in vivo. Table 4 compares results obtained in animal models with various types of collagen scaffolds, among them cross-linked, compacted through cellmediated contraction process, plastic-compressed and mechanically stimulated prior to implantation. After several weeks or months in vivo, most scaffolds exhibited partial replacement by neo-fibers and neo-vascularization in certain cases. The importance of mechanical prestimulation of cellularized scaffolds prior to implantation is highlighted in the works from Juncosa-Melvin et al. (2006, 2007) [227], [228], and Shearn et al. (2007) [230]. Twelve weeks after implantation in rabbit patellar tendon defects the maximal force obtained could reach $70 \%$ of normal tendons, which is comparable to the study led by Cavallaro et al. (1993) [118] using knitted EDCcrosslinked fibers with results obtained twelve weeks after implantation in dog anterior cruciate ligament.

Finally, this review shows that as bioengineering techniques improve, more complex tissues are achievable. Thus, some examples of myo-tendinous or bone-tendon junction reconstructions have been presented, illustrating the further increase of complexity. The development of artificial junctions could be paramount to improve overall scaffold efficiency and reliability, as well as to increase our understanding on the interactions between different biomaterials and cells. 


\begin{tabular}{|c|c|c|c|c|c|c|}
\hline $\begin{array}{l}\text { Techn } \\
\text { ique }\end{array}$ & Scaffold/parameters & $\begin{array}{l}\text { Animal models / } \\
\text { Sample size }\end{array}$ & $\begin{array}{l}\text { Implantation } \\
\text { site / } \\
\text { Controls }\end{array}$ & \multicolumn{2}{|c|}{ Main results } & Refs \\
\hline \multirow{3}{*}{$\frac{\bar{c}}{\frac{0}{2}}$} & $\begin{array}{l}\text { Parallel crosslinked collagen } \\
\text { fibers }(200) \text { in an } \\
\text { uncrosslinked collagen } \\
\text { matrix } \\
\text { - Fiber diameter: } 20 \text { or } 50 \mu \mathrm{m} \\
\text { - Cross-linking: GLUT or DHTC }\end{array}$ & $\begin{array}{l}\text { Rabbit } \\
n=5 \text { for each group }\end{array}$ & Subcutaneous & \multicolumn{2}{|c|}{$\begin{array}{l}\text { After } 4 \text { weeks: } \\
\text { - DHTC-crosslinked fibers mostly degraded and replaced } \\
\text { by fibrous tissue } \\
\text { - GLUT-crosslinked fibers mostly intact, surrounded by } \\
\text { inflammatory cells } \\
\text { - No influence of initial fiber diameter }\end{array}$} & $\begin{array}{l}\text { [Dunn } \\
1993 \text { ] }\end{array}$ \\
\hline & \multirow[t]{2}{*}{$\begin{array}{l}\text { Knitted collagen fabrics } \\
\text { - Dry diameter: } 25 \mu \mathrm{m} \\
\text { - Cross-linking : EDC }\end{array}$} & Dog & $\begin{array}{l}\text { Anterior } \\
\text { Cruciate } \\
\text { Ligament }\end{array}$ & \multicolumn{2}{|c|}{$\begin{array}{l}\text { After } 12 \text { weeks: } \\
\text { - Applied force by the operated limb at } 70 \% \text { of control } \\
\text { - Threads remain intact with disorganized cellular } \\
\text { ingrowth } \\
\text { - Neovascularization, normal size collagen fibrils in the } \\
\text { neoligament }\end{array}$} & \multirow[t]{2}{*}{$\begin{array}{l}\text { [Cavallaro } \\
1994]\end{array}$} \\
\hline & & $\begin{array}{l}\text { Rat } \\
\mathrm{n}=5\end{array}$ & $\begin{array}{l}\text { Abdominal } \\
\text { wall defect }\end{array}$ & $\begin{array}{l}\text { After } 3 \text { weeks: } \\
\text { - Neovascularization and } \\
\text { fibroblastic cellular infiltrate }\end{array}$ & $\begin{array}{l}\text { After } 12 \text { weeks: } \\
\text { - No herniation }\end{array}$ & \\
\hline 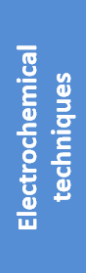 & $\begin{array}{l}\text { Braided ELAC threads (9) } \\
\text { - Threads diameter : } 200-300 \\
\mu \mathrm{m} \text { thick, } 400-500 \mu \mathrm{m} \text { wide } \\
\text { - Cross-linking: Genipin }\end{array}$ & $\begin{array}{l}\text { Rabbit } \\
\text { Sacrificed at } 4 \text { and } 8 \text { months } \\
\text { ( } \mathrm{n}=3 \text { each) }\end{array}$ & $\begin{array}{l}\text { Patellar } \\
\text { tendon } \\
\text { (incised along the } \\
\text { length) }\end{array}$ & $\begin{array}{l}\text { After } 4 \text { months: } \\
\text { - Low degradation of the ELAC } \\
\text { scaffold } \\
\text { - Cross-sectional area, mechanical } \\
\text { properties and tendon-fascicles } \\
\text { content of the PTs treated with } \\
\text { ELAC optimized / controls } \\
\text { - Low-grade granulomatous } \\
\text { inflammation }\end{array}$ & $\begin{array}{l}\text { After } 8 \text { months : } \\
\text { - Differences / } \\
\text { controls less } \\
\text { evident } \\
\text { - Diminished } \\
\text { inflammation }\end{array}$ & $\begin{array}{l}\text { [Kishore } \\
\text { 2012] }\end{array}$ \\
\hline \multirow{3}{*}{ 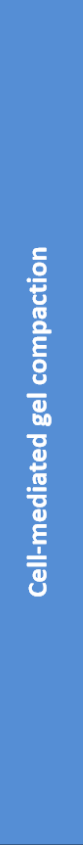 } & $\begin{array}{l}\text { Bone derived MSCs- } \\
\text { collagen gel composite } \\
\text { - Contraction: pre-tensioned } \\
\text { suture }\end{array}$ & $\begin{array}{l}\text { Rabbit } \\
\text { Sacrificed at } 4,8 \text {, or } 12 \text { weeks } \\
\text { ( } n=16 \text { each) } \\
5 \text { animals used for } \\
\text { establishing normal } \\
\text { biomechanical properties }\end{array}$ & $\begin{array}{l}\text { Achilles } \\
\text { tendon } \\
\text { ( } 1 \mathrm{~cm} \text { long gap } \\
\text { defect) } \\
\text { Controls: } \\
\text { contralateral } \\
\text { tendons } \\
\text { implanted with } \\
\text { suture material } \\
\text { only }\end{array}$ & $\begin{array}{l}\text { After } 4 \text { weeks: } \\
\text { - Stiffness is } 1 / 2 \text { and maximum } \\
\text { force } 2 / 3 \text { of normal tendons, } 2 X / \\
\text { controls }\end{array}$ & $\begin{array}{l}\text { At } 12 \text { weeks: } \\
\text { - Modulus } 1 / 2 \text { of } \\
\text { normal tendons, } 2 X \\
\text { / controls } \\
\text { - Histology: } \\
\text { collagen bands } \\
\text { which volume, } \\
\text { density and crimp } \\
\text { pattern are } \\
\text { enhanced over } \\
\text { time, more mature } \\
\text { / controls }\end{array}$ & $\begin{array}{l}\text { [Young } \\
1998]\end{array}$ \\
\hline & $\begin{array}{l}\text { Bone marrow MSCs- } \\
\text { collagen composites } \\
\text { - Contraction: sutures }\end{array}$ & $\begin{array}{l}\text { Rabbit } \\
2 \text { groups (n=43 each): } \\
\text {-with } 1.10^{6} / \mathrm{ml} \text { cells and } 4 . \\
10^{6} / \mathrm{mL} \text { cells composites in } \\
\text { each tendon, } \\
\text { - with } 8.10^{6} / \mathrm{mL} \text { cells in first } \\
\text { tendon and defect left } \\
\text { untreated in the second one } \\
8 \text { animals to assess tendon } \\
\text { normal properties }\end{array}$ & $\begin{array}{l}\text { Patellar } \\
\text { tendon } \\
\text { central defects }\end{array}$ & $\begin{array}{l}\text { At } 12 \text { and } 26 \text { weeks: } \\
\text {-Significant improvement of the } \\
\text { biomechanical properties / natural } \\
\text { repairs }\end{array}$ & $\begin{array}{l}\text { At } 26 \text { weeks: } \\
\text { - Maximum stress } \\
\text { is } 1 / 4 \text { of normal } \\
\text { tendon portion } \\
\text { - No additional } \\
\text { benefit of } \\
\text { increasing cell } \\
\text { density } \\
\text { - Formation of } \\
\text { ectopic bone in } \\
28 \% \text { of all } \\
\text { composite grafted } \\
\text { repairs }\end{array}$ & $\begin{array}{l}{[\text { [Awad }} \\
2003]\end{array}$ \\
\hline & $\begin{array}{l}\text { MSCs-collagen composites } \\
\text { - Contraction: in silicon dishes } \\
\text { between two posts }\end{array}$ & $\begin{array}{l}\text { Rabbit } \\
2 \text { groups : } \\
\text {-with cells : } 40.000 \text { or } 80.000 \\
\text { cells/mg collagen)( } n=16) \\
\text { - without cells }(n=6)\end{array}$ & $\begin{array}{l}\text { Patellar } \\
\text { tendon } \\
\text { central third } \\
\text { defects }\end{array}$ & \multicolumn{2}{|c|}{$\begin{array}{l}\text { After } 12 \text { weeks: } \\
\text { - No significant difference in material and histological } \\
\text { properties between the two cell concentrations and } \\
\text { similar to acellular implants } \\
\text { - Average linear modulus } \sim 20 \% \text { of normal values }\end{array}$} & $\begin{array}{l}\text { [Juncosa- } \\
\text { Melvin } \\
\text { 2005] }\end{array}$ \\
\hline$\frac{\frac{5}{5}}{\frac{0}{4}}$ & $\begin{array}{l}\text { Plastic-compressed } \\
\text { collagen gels } \\
\text { - Seeded or not with rabbit } \\
\text { flexor tendon cells } \\
\text {-20-40 } \mu \text { m thick } \\
\text {-rolled to produce spiral rolls } \\
22 \mathrm{~mm} \text { in length } \times 2.25 \mathrm{~mm} \text { in } \\
\text { diameter }\end{array}$ & $\begin{array}{l}\text { Rabbit } \\
\text { Sacrificed at } 3 \text { time points: } \\
1 \text { week }(n=5) \text {, } \\
3 \text { weeks }(n=4) \text {, } \\
5 \text { weeks }(n=4)\end{array}$ & $\begin{array}{l}\text { Intercostal } \\
\text { spaces } \\
3 \text { cellular } \\
\text { constructs on one } \\
\text { side of the chest } \\
\text { and } 3 \text { acellular } \\
\text { constructs on the } \\
\text { other one } \\
\end{array}$ & \multicolumn{2}{|c|}{$\begin{array}{l}\text { After } 5 \text { weeks: } \\
\text { - Vascularization with a stronger response in the cellular } \\
\text { constructs } \\
\text { - Collagen remodeling and tensile mechanical strength } \\
\text { enhanced in the cell-seeded gels }\end{array}$} & $\begin{array}{l}\text { [Mudera } \\
\text { 2007] }\end{array}$ \\
\hline \multirow{2}{*}{ 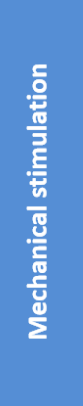 } & $\begin{array}{l}\text { Collagen type I sponge with } \\
\text { rabbit bone marrow MSCs } \\
\text { - Either stimulated or non- } \\
\text { stimulated constructs ( } 2 \text { weeks } \\
\text { with } 4 \% \text { strain, } 1 \mathrm{~Hz} \text { cycle every } \\
5 \mathrm{~min}, 8 \mathrm{~h} / \text { day) }\end{array}$ & $\begin{array}{l}\text { Rabbit } \\
\mathrm{n}=10\end{array}$ & $\begin{array}{l}\text { Patellar } \\
\text { tendon } \\
\text { central third } \\
\text { defects }\end{array}$ & \multicolumn{2}{|c|}{$\begin{array}{l}\text { After } 12 \text { weeks: } \\
\text { - Maximal force } 70 \% \text { of normal tendons, vs } 55 \% \text { for non- } \\
\text { stimulated constructs }\end{array}$} & $\begin{array}{l}\text { [Juncosa- } \\
\text { Melvin } \\
\text { 2006] } \\
\text { [Juncosa- } \\
\text { Melvin } \\
\text { 2007] }\end{array}$ \\
\hline & $\begin{array}{l}\text { Mixture of rabbit bone } \\
\text { marrow MSCs and collagen } \\
\text { gels combined with } \\
\text { collagen sponges } \\
\text { Either non stimulated or } \\
\text { stimulated constructs ( } 2 \mathrm{w} \text {. } \\
\text { with } 4 \% \text { strain, } 1 \mathrm{~Hz} \text { cycle every } \\
5 \mathrm{~min}, 8 \mathrm{~h} / \text { day) }\end{array}$ & $\begin{array}{l}\text { Rabbit } \\
\mathrm{n}=6\end{array}$ & $\begin{array}{l}\text { Patellar } \\
\text { tendon } \\
\text { central third } \\
\text { defects }\end{array}$ & \multicolumn{2}{|c|}{$\begin{array}{l}\text { After } 12 \text { weeks: } \\
\text { - Averaged linear stiffness } 80 \% \text { of normal values, vs } 50 \% \\
\text { for non-stimulated constructs } \\
\text { - Maximal force } 65 \% \text { vs } 60 \% \text { for non-stimulated constructs }\end{array}$} & $\begin{array}{l}\text { [Shearn } \\
2007]\end{array}$ \\
\hline
\end{tabular}




\section{CONFLICT OF INTEREST}

The authors confirm that this article content has no conflict of interest.

\section{ACKNOWLEDGEMENTS}

The authors would like to thank David Pinto, Francisco M. Fernandes and Léa-Laetitia Pontani for critical reading of the manuscript. C. R. and L. P. were supported by a French Ministère de la Recherche fellowship.

\section{REFERENCES}

[1] Morais DS, Torres J, Guedes RM, et al. Current Approaches and Future Trends to Promote Tendon Repair. Ann Biomed Eng 2015; 43:2025-2035.

[2] Thomopoulos S, Parks WC, Rifkin DB, et al. Mechanisms of tendon injury and repair: TENDON INJURY AND REPAIR. J Orthop Res 2015; 33: 832-839.

[3] Young JS, Maffulli N. Etiology and epidemiology of Achilles tendon problems. In: Maffulli N, Almekinders L, Eds. The Achilles Tendon. Springer 2007: pp. 39-49.

[4] Riley G. Tendinopathy-from basic science to treatment. Nat Clin Pract Rheumatol 2008; 4: 82-89.

[5] Lomas AJ, Ryan CNM, Sorushanova A, et al. The past, present and future in scaffold-based tendon treatments. Adv Drug Deliv Rev 2015; 84: 257-277.

[6] Lewis T, Cook J. Fluoroquinolones and Tendinopathy: A Guide for Athletes and Sports Clinicians and a Systematic Review of the Literature. J Athl Train 2014; 49:422-427.

[7] Oliva F, Via AG, Maffulli N. Calcific tendinopathy of the rotator cuff tendons. Sports Med Arthrosc Rev 2011; 19: 237-243.

[8] Clayton RAE, Court-Brown CM. The epidemiology of musculoskeletal tendinous and ligamentous injuries. Injury 2008; 39: 1338-1344.

[9] De Jong JP, Nguyen JT, Sonnema AJM, et al. The Incidence of Acute Traumatic Tendon Injuries in the Hand and Wrist: A 10-Year Population-based Study. Clin Orthop Surg 2014; 6: 196, 2014.

[10] Sun C. Zhuo Q, Chai W, et al. Conservative interventions for treating Achilles tendon ruptures (Protocol). Cochrane Database of Systematic Reviews 2013. The Cochrane
Collaboration. Published by John Wiley \& Sons, Ltd. DOI: 10.1002/14651858.CD010765

[11] Scott A, Ashe MC. Common Tendinopathies in the Upper and Lower Extremities. Curr Sports Med Rep 2006; 5:233-241.

[12] Sanders TL, Maradit Kremers H, Bryan AJ, et $a l$. The Epidemiology and Health Care Burden of Tennis Elbow: A Population-Based Study. Am J Sports Med 2015; 43: 1066-1071.

[13] Pluim BM. Tennis injuries: occurrence, aetiology, and prevention. $\mathrm{Br} J$ Sports Med 2006; 40: 415-423.

[14] European Agency for Safety and Health at Work. OSH in figures: Work-related musculoskeletal disorders in the EU - Facts and figures; 2010. Available from: osha.europa.eu/fr/tools-and-

publications/publications/reports/TERO09009 ENC

[15] Health and Safety Executive, UK. Workrelated Musculoskeletal disorder (WRMSDs) Statistics, Great Britain, 2015. Available from: hse.gov.uk/statistics/

[16] Agency for Healthcare Research and Quality. Comparative Effectiveness of the Nonoperative and Operative Treatments for Rotator Cuff Tears; 2010. Available from: ahrq.gov

[17] European Agency for Safety and Health at Work. Work-related neck and upper limb musculoskeletal disorders; 1999. Available from: osha.europa.eu/en/tools-andpublications/publications/reports/201

[18] Andarawis-Puri N, Flatow EL, Soslowsky LJ. Tendon basic science: Development, repair, regeneration, and healing. J Orthop Res 2015; 33: 780-784.

[19] Rawson S, Cartmell S, Wong J. Suture techniques for tendon repair; a comparative review. Muscles Ligaments Tendons J 2013; 3: 220, 2013.

[20] Squier CA, Bausch WH. Three-dimensional organization of fibroblasts and collagen fibrils in rat tail tendon. Cell Tissue Res 1984; 238: 319-327.

[21] Zhang G, Young BB, Ezura Y, et al. Development of tendon structure and function: regulation of collagen fibrillogenesis. J Musculoskelet Neuronal Interact 2005; 5: 521.

[22] Screen HRC, Berk DE, Kadler KE, et al. Tendon Functional Extracellular Matrix. J Orthop Res 2015; 33: 793-799. 
[23] Kadler KE, Baldock C, Bella J, et al. Collagens at a glance. J Cell Sci 2007; 120: 1955-1958.

[24] Pohlhammer J , O’Brien Jr WD, Dependence of the ultrasonic scatter coefficient on collagen concentration in mammalian tissues. J Acoust Soc Am 1981; 69: 283, 1981.

[25] Scott JE, Chemical morphology: The chemistry of our shape, in vivo and in vitro. Struct Chem 2007; 18: 257-265.

[26] Birch HL. Tendon matrix composition and turnover in relation to functional requirements. Int J Exp Pathol 2007; 88: 241-248.

[27] Bancelin S, Couture CA, Légaré K et al. Fast interferometric second harmonic generation microscopy. Biomed. Opt. Express 2016; 7: 399-408.

[28] Gusachenko I, Tran V, Houssen YG, et al. Polarization-Resolved Second-Harmonic Generation in Tendon upon Mechanical Stretching. Biophys J 2012; 102: 2220-2229.

[29] Fouré A. New Imaging Methods for Noninvasive Assessment of Mechanical, Structural, and Biochemical Properties of Human Achilles Tendon: A Mini Review. Front Physiol 2016; 7: 324.

[30] Hulmes DJS. Building Collagen Molecules, Fibrils, and Suprafibrillar Structures. J Struct Biol 2002; 137: 2-10.

[31] Benjamin M, Kaiser E, Milz S. Structurefunction relationships in tendons: a review. J Anat 2008; 212: 211-228.

[32] Kannus P. Structure of the tendon connective tissue. Scand J Med Sci Sports 2000; 10: 312320.

[33] Nicholls SP, Gathercole LJ, Keller A, et al. Crimping in rat tail tendon collagen: morphology and transverse mechanical anisotropy. Int J Biol Macromol 1983; 5: 283288.

[34] Dlugosz J, Gathercole LJ, Keller A. Transmission electron microscope studies and their relation to polarizing optical microscopy in rat tail tendon. Micron 1978; 9: 71-82.

[35] Wang J H-C. Mechanobiology of tendon. J. Biomech 2006; 39: 1563-1582.

[36] Shah JS, Palacios E, Palacios L. Development of crimp morphology and cellular changes in chick tendons. Dev Biol 1982; 94: 499-504.

[37] Herchenhan A, Kalson NS, Holmes DF, et al. Tenocyte contraction induces crimp formation in tendon-like tissue. Biomech Model Mechanobiol 2012; 11: 449-459.

[38] Hu XW, Knight DP, Chapman JA. The effect of non-polar liquids and non-ionic detergents on the ultrastructure and assembly of rat tail tendon collagen fibrils in vitro. Biochim Biophys Acta 1997; 1334: 327-337.

[39] Cartmell JS, Dunn MG. Effect of chemical treatments on tendon cellularity and mechanical properties. J. Biomed Mater Res 2000; 49: 134-140.

[40] Vidal B de C. Image analysis of tendon helical superstructure using interference and polarized light microscopy. Micron 2003; 34: 423-432.

[41] Grytz R, Meschke G. Constitutive modeling of crimped collagen fibrils in soft tissues. J Mech Behav Biomed Mater 2009; 2: 522-533.

[42] Reese SP, Maas SA, Weiss JA. Micromechanical models of helical superstructures in ligament and tendon fibers predict large Poisson's ratios. J Biomech 2010; 43: 1394-1400.

[43] Livolant F, Leforestier A. Condensed phases of DNA: structures and phase transitions. Prog Polym Sci 1996; 21: 1115-1164.

[44] Murthy NS. Liquid crystallinity in collagen solutions and magnetic orientation of collagen fibrils. Biopolymers 1984; 23: 1261-1267.

[45] Maeda H. An Atomic Force Microscopy Study of Ordered Molecular Assemblies and Concentric Ring Patterns from Evaporating Droplets of Collagen Solutions. Langmuir 1999; 15: 8505-8513.

[46] Giraud-Guille MM. Liquid crystallinity in condensed type I collagen solutions: a clue to the packing of collagen in extracellular matrices. J Mol Biol 1992; 224: 861-873.

[47] De Sa Peixoto P, Deniset-Besseau A, SchanneKlein M-C, et al. Quantitative assessment of collagen I liquid crystal organizations: role of ionic force and acidic solvent, and evidence of new phases. Soft Matter 2011; 7: 11203, 2011.

[48] Williams IF, Craig AS, Parry DAD, et al. Development of collagen fibril organization and collagen crimp patterns during tendon healing. Int J Biol Macromol 1985; 7: 275282.

[49] Müller SA, Todorov A, Heisterbach PE et al. Tendon healing: an overview of physiology, biology, and pathology of tendon healing and systematic review of state of the art in tendon bioengineering. Knee Surg Sports Traumatol Arthrosc 2015; 23: 2097-2105.

[50] Nourissat G, Berenbaum F, Duprez D. Tendon injury: from biology to tendon repair. Nat Rev Rheumatol 2015; 11: 223-233.

[51] Wada A, Kubota H, Miyanishi K, et al. Comparison of postoperative early active mobilization and immobilization in vivo 
utilising a four-strand flexor tendon repair. $\mathbf{J}$ Hand Surg Edinb Scotl 2001; 26: 301-306.

[52] Childress MA, Beutler A. Management of chronic tendon injuries. Am Fam Physician 2013; 87: 486-490.

[53] Khan KM, Scott A. Mechanotherapy: how physical therapists' prescription of exercise promotes tissue repair. Br J Sports Med 2009; 43: 247-252.

[54] Sundman EA, Cole BJ, Fortier LA. Growth factor and catabolic cytokine concentrations are influenced by the cellular composition of platelet-rich plasma. Am J Sports Med 2011; 39: 2135-2140.

[55] Gelberman RH, Boyer MI, Brodt MD, et al. The effect of gap formation at the repair site on the strength and excursion of intrasynovial flexor tendons. An experimental study on the early stages of tendon-healing in dogs. $\mathrm{J}$ Bone Joint Surg Am 1999; 81: 975-982.

[56] Buckley PS, Pedowitz DI. Bone Reduction Clamp to Gain Length in Repairing Chronic Achilles Tendon Ruptures. Orthopedics 2016; 39: e1223-e1225.

[57] Feldbrin Z, Hendel D, Lipkin A, et al. Achilles tendon rupture and our experience with the achillon device. Isr Med Assoc J 2010; 12: 609-612.

[58] Huffard B, O'Loughlin PF, Wright $\mathrm{T}$ et al. Achilles tendon repair: Achillon system vs. Krackow suture: An anatomic in vitro biomechanical study. Clin Biomech 2008; 23: 1158-1164.

[59] Wang JHC. Mechanobiology of tendon. J Biomech 2006; 39: 1563-1582.

[60] Gomes ME, Reis RL, Rodrigues MT, Eds. Tendon Regeneration: Understanding Tissue Physiology and Development to Engineer Functional Substitutes. Academic Press 2015.

[61] Maquirriain J. Achilles Tendon Rupture: Avoiding Tendon Lengthening during Surgical Repair and Rehabilitation. Yale J Biol Med 2011; 84: 289-300.

[62] Schliemann B, Grüneweller N, Yao D, et al. Biomechanical evaluation of different surgical techniques for treating patellar tendon ruptures. Int Orthop 2016; 40: 1717-1723.

[63] Hohendorff B, Siepen W, Spiering L, et al. Long-term Results after Operatively Treated Achilles Tendon Rupture: Fibrin Glue versus Suture. J Foot Ankle Surg 2008; 47: 392-399.

[64] Rose S, Prevoteau A, Elzière $\mathrm{P}$, et al. Nanoparticle solutions as adhesives for gels and biological tissues. Nature 2014; 505: $382-$ 385 .
[65] Erol B, Kocaoğlu B, Esemenli T. Spiralshaped Metallic Implant in the Treatment of Achilles Tendon Ruptures: An Experimental Study on the Achilles Tendon of Sheep. J. Foot Ankle Surg 2007; 46: 155-16.

[66] Ağır İ, Aytekin MN, Başçı O, et al. TendonHolding Capacities of Two Newly Designed Implants for Tendon Repair: An Experimental Study on the Flexor Digitorum Profundus Tendon of Sheep. Open Orthop J 2014; 8: 135-139.

[67] Wolfe SW, Willis AA, Campbell D, et al. Biomechanic Comparison of the Teno Fix Tendon Repair Device With the Cruciate and Modified Kessler Techniques. J Hand Surg 2007; 32: 356-366.

[68] Lacoste S, Féron JM, Cherrier B. Percutaneous Tenolig® repair under intra-operative ultrasonography guidance in acute Achilles tendon rupture. Orthop Traumatol Surg Res 2014; 100: 925-930.

[69] Magnussen RA, Glisson RR, Moorman CT. Augmentation of Achilles Tendon Repair With Extracellular Matrix Xenograft A Biomechanical Analysis. Am J Sports Med 2011; 39: 1522-1527.

[70] Beskin JL, Sanders RA, Hunter SC, et al. Surgical repair of Achilles tendon ruptures. Am J Sports Med 1987; 15: 1-8.

[71] Carmont MR, Maffulli N. Less invasive Achilles tendon reconstruction. BMC Musculoskelet Disord 2007; 8: 100.

[72] Ebied AM, Foda AAA. Less Invasive Reconstruction of Chronic Achilles Tendon Rupture with free Semitendinosus Tendon Autograft - A case Series. Int J Orthop 2016; 3: 539-543.

[73] Shewy MTE, Barbary HME, Abdel-Ghani H. Repair of Chronic Rupture of the Achilles Tendon Using 2 Intratendinous Flaps From the Proximal Gastrocnemius-Soleus Complex. Am J Sports Med 2009; 37: 1570-1577.

[74] Phipatanakul WP, Petersen SA. Porcine small intestine submucosa xenograft augmentation in repair of massive rotator cuff tears. Am $\mathrm{J}$ Orthop Belle Mead NJ 2009; 38: 572-575.

[75] Sclamberg SG, Tibone JE, Itamura JM, et al. Six-month magnetic resonance imaging follow-up of large and massive rotator cuff repairs reinforced with porcine small intestinal submucosa. J Shoulder Elb Surg 2004; 13: 538-541.

[76] Berlet GC, Hyer CF, Lee TH, et al. Collagen Ribbon Augmentation of Achilles Tendon 
Tears: A Biomechanical Evaluation. J Foot Ankle Surg 2014; 53: 298-302.

[77] Song L, Olsen RE, Spalazzi JP, et al. Biomechanical Evaluation of Acellular Collagen Matrix Augmented Achilles Tendon Repair in Sheep. J. Foot Ankle Surg 2010; 49: 438-441.

[78] Lee DK. A Preliminary Study on the Effects of Acellular Tissue Graft Augmentation in Acute Achilles Tendon Ruptures. J Foot Ankle Surg 2008; 47: 8-12.

[79] Hollawell S, Baione W. Chronic Achilles Tendon Rupture Reconstructed With Achilles Tendon Allograft and Xenograft Combination. J Foot Ankle Surg 2015; 54: 1146-1150.

[80] Herbert A, Jones GL, Ingham E. A biomechanical characterisation of acellular porcine super flexor tendons for use in anterior cruciate ligament replacement: Investigation into the effects of fat reduction and bioburden reduction bioprocesses. J Biomech 2015; 48: 22-29.

[81] Branch JP. A Tendon Graft Weave Using an Acellular Dermal Matrix for Repair of the Achilles Tendon and Other Foot and Ankle Tendons. J Foot Ankle Surg 2011; 50: 257265.

[82] Gaspar D, Spanoudes K, Holladay C, et al. Progress in cell-based therapies for tendon repair. Adv Drug Deliv Rev 2015; 84: 240 256.

[83] Güngörmüş C, Kolankaya D, and Aydin E. Histopathological and biomechanical evaluation of tenocyte seeded allografts on rat Achilles tendon regeneration. Biomaterials vol. 2015; 51: 108-118.

[84] Kew SJ, Gwynne JH, Enea D, et al. Regeneration and repair of tendon and ligament tissue using collagen fibre biomaterials. Acta Biomater 2011; 7: 32373247.

[85] Stapp MD. Implantable materials and grafts in tendon surgery. In: Reconstructive surgery of the foot and leg: update '93. Tucker, GA: Podiatry Institute Publishing Co. 1993; pp. 289-292.

[86] Williams RD, August SF. Experimental evaluation of a Teflon tendon prosthesis. Am J Surg 1964; 107: 913-916.

[87] Holtz M, Midenberg ML, Kirschenbaum SE, Utilization of a silastic sheet in tendon repair of the foot. J Foot Surg 1982; 21: 253-259.

[88] Morrey MC, Barlow JD, Abdel MP, et al. Synthetic Mesh Augmentation of Acute and
Subacute Quadriceps Tendon Repair. Orthopedics 2016; 39: e9-e13.

[89] Abdullah S. Usage of synthetic tendons in tendon reconstruction. BMC Proc 2015; 9: p. A68.

[90] Melvin A, Litsky A, Mayerson J, et al. An artificial tendon with durable muscle interface. J Orthop Res Off Publ Orthop Res Soc 2010; 28: 218-224.

[91] Jenkins DH, McKibbin B. The role of flexible carbon-fibre implants as tendon and ligament substitutes in clinical practice. A preliminary report. J Bone Joint Surg Br 1980; 62-B: 497499.

[92] Corey SV. Tendon grafts and implants. In: Reconstructive surgery of the foot and leg: update '88. Tucker, GA: Podiatry Institute Publishing Co. 1988; pp. 58-61.

[93] Roberts JM, Goldstrohm GL, Brown TD, et al. Comparison of unrepaired, primarily repaired, and polyglactin mesh-reinforced Achilles tendon lacerations in rabbits. Clin Orthop 1983; 181: 244-249.

[94] Howard CB, McKibbin B, Ralis ZA. The use of Dexon as a replacement for the calcaneal tendon in sheep. Bone Jt J 1985; 67-B: 313316.

[95] Liem MD, Zegel HG, Balduini FC, et al. Repair of Achilles tendon ruptures with a polylactic acid implant: assessment with MR imaging. AJR Am J Roentgenol 1991; 156: 769-773.

[96] Alexander H, Weiss AB, Parsons JR. Absorbable polymer-filamentous carbon composites--a new class of tissue scaffolding materials. Aktuelle Probl Chir Orthop 1983; 26: 78-91.

[97] Cao Y, Liu Y, Liu W, et al. Bridging tendon defects using autologous tenocyte engineered tendon in a hen model. Plast Reconstr Surg 2002; 110: 1280-1289.

[98] Shoaib A, Mishra V. Surgical repair of symptomatic chronic achilles tendon rupture using synthetic graft augmentation. Foot Ankle Surg 2016. doi.org/10.1016/j.fas.2016.04.006

[99] Verdiyeva G, Koshy K, Glibbery N. Tendon Reconstruction with Tissue Engineering Approach-A Review. J Biomed Nanotechnol 2015; 11: 1495-1523.

[100] Ladd MR, Lee SJ, Stitzel JD, et al. Coelectrospun dual scaffolding system with potential for muscle-tendon junction tissue engineering. Biomaterials 2011; 32: 15491559. 
[101] Jung H-J, Fisher MB, Woo S L-Y. Role of biomechanics in the understanding of normal, injured, and healing ligaments and tendons. BMC Sports Sci Med Rehabil 2009; 1:1-9.

[102] Tong WY, Shen W, Yeung CWF, et al. Functional replication of the tendon tissue microenvironment by a bioimprinted substrate and the support of tenocytic differentiation of mesenchymal stem cells. Biomaterials 2012; 33: 7686-7698.

[103] Park SA, Kim IA, Lee YJ, et al. Biological responses of ligament fibroblasts and gene expression profiling on micropatterned silicone substrates subjected to mechanical stimuli. J Biosci Bioeng 2006; 102: 402-412.

[104] Wang JH, Jia F, Gilbert TW, et al. Cell orientation determines the alignment of cellproduced collagenous matrix. J Biomech 2003; 36: 97-102.

[105] van Delft FCMJM, van den Heuvel FC, Loesberg WA, et al. Manufacturing substrate nano-grooves for studying cell alignment and adhesion. Microelectron Eng 2008; 85: 1362 1366.

[106] Mertz L. What Is Biocompatibility?: A New Definition Based on the Latest Technology. IEEE Pulse 2013; 4: 14-15.

[107] Use of International Standard ISO 10993-1, 'Biological evaluation of medical devices Part 1: Evaluation and testing within a risk management process'. U.S. Department of Health and Human Services Food and Drug Administration Center for Devices and Radiological Health, Jun. 2016.

[108] Hutmacher DW. Scaffolds in tissue engineering bone and cartilage. Biomaterials 2000; 21: 2529-2543.

[109] Badylak SF, Tullius R, Kokini K, et al. The use of xenogeneic small intestinal submucosa as a biomaterial for Achille's tendon repair in a dog model. J Biomed Mater Res 1995; 29: 977-985.

[110] Gilbert TW, Stewart-Akers AM, SimmonsByrd A, et al. Degradation and remodeling of small intestinal submucosa in canine achilles tendon repair. J Bone Jt Surg Am 2007; 89: 621-630.

[111] Kew SJ, Gwynne JH, Enea D, et al., Regeneration and repair of tendon and ligament tissue using collagen fibre biomaterials. Acta Biomater 2011; 7: 32373247.

[112] Glowacki J, Mizuno S. Collagen scaffolds for tissue engineering. Biopolymers 2008; 89: 338-344.
[113] Barczyk M, Carracedo S, Gullberg D. Integrins, Cell Tissue Res 2010; 339: 269-280.

[114] Jokinen $\mathrm{J}$, et al. Integrin-mediated cell adhesion to type I collagen fibrils. J Biol Chem 2004; 279: 31956-31963.

[115] Murphy SV, Skardal A, Atala A. Evaluation of hydrogels for bio-printing applications. J Biomed Mater Res A 2013;101A: 272-284.

[116] Walters BD, Stegemann JP. Strategies for directing the structure and function of threedimensional collagen biomaterials across length scales. Acta Biomater 2014; 10: 1488 1501.

[117] Muller SA, Durselen L, Heisterbach P, et al. Effect of a Simple Collagen Type I Sponge for Achilles Tendon Repair in a Rat Model. Am J Sports Med 2016; 44: 1998-2004.

[118] Cavallaro JF, Kemp PD, Kraus KH. Collagen fabrics as biomaterials. Biotechnol Bioeng vol. 1994; 43: 781-791.

[119] Truhlsen SM, Fitzpatrick J. The extruded collagen suture: tissue reaction and absorption. Arch Ophthalmol 1965; 74: 371-374.

[120] Enea D, Henson F, Kew S, et al. Extruded collagen fibres for tissue engineering applications: effect of crosslinking method on mechanical and biological properties. J Mater Sci Mater Med 2011; 22: 1569-1578.

[121] Zeugolis DI, Paul RG, Attenburrow G. Factors influencing the properties of reconstituted collagen fibers prior to self-assembly: Animal species and collagen extraction method. J Biomed Mater Res A 2008; 86A: 892-904.

[122] Pins GD, Christiansen DL, Patel R, et al. Selfassembly of collagen fibers. Influence of fibrillar alignment and decorin on mechanical properties. Biophys J 1997; 73: 2164-2172.

[123] Wang MC, Pins GD, Silver FH. Collagen fibres with improved strength for the repair of soft tissue injuries. Biomaterials 1994; 15: 507-512.

[124] Lai ES, Anderson CM, Fuller GG. Designing a tubular matrix of oriented collagen fibrils for tissue engineering. Acta Biomater 2011; 7: 2448-2456.

[125] Dunn MG, Avasarala PN, Zawadsky JP. Optimization of extruded collagen fibers for ACL reconstruction. J Biomed Mater Res 1993; 27: 1545-1552.

[126] Kato YP, Christiansen DL, Hahn RA, et al. Mechanical properties of collagen fibres: a comparison of reconstituted and rat tail tendon fibres. Biomaterials 1989; 10: 38-42.

[127] Cornwell K. Collagen and Fibrin Biopolymer Microthreads for Bioengineered Ligament 
Generation: a Dissertation. GSBS Diss. Theses, May 2007.

[128] Huang Z-M, Zhang YZ, Kotaki, M, et al. A review on polymer nanofibers by electrospinning and their applications in nanocomposites. Compos Sci Technol 2003; 63: 2223-2253.

[129] Teo WE, Ramakrishna S. A review on electrospinning design and nanofibre assemblies. Nanotechnology 2006; 17: R89R106.

[130] Dong B, Arnoult O, Smith ME, et al. Electrospinning of Collagen Nanofiber Scaffolds from Benign Solvents. Macromol Rapid Commun 2009; 30: 539-542.

[131] Choktaweesap N, Arayanarakul K, Aht-Ong $\mathrm{D}$, et al. Electrospun gelatin fibers: effect of solvent system on morphology and fiber diameters. Polym J 2007; 39: 622-631.

[132] Wan Y-Q, He J-H, Yu J-Y, et al. Electrospinning of high-molecule PEO solution. J Appl Polym Sci 2007; 103: 38403843.

[133] Bürck J, Heissler, Geckler U, et al. Resemblance of Electrospun Collagen Nanofibers to Their Native Structure. Langmuir 2013; 29: 1562-1572.

[134] Matthews JA, Wnek GE, Simpson DG, et al. Electrospinning of Collagen Nanofibers. Biomacromolecules 2002; 3: 232-238.

[135] Matthews JA, Boland ED, Wnek GE, et al. Electrospinning of collagen type II: a feasibility study. J Bioact Compat Polym 2003; 18: 125-134.

[136] Rho KS, Jeong L, Lee G, et al. Electrospinning of collagen nanofibers: Effects on the behavior of normal human keratinocytes and early-stage wound healing. Biomaterials, 2006; 27: 14521461.

[137] Zhong SP, Teo WE, Zhu X, et al. Development of a novel collagen-GAG nanofibrous scaffold via electrospinning. Mater Sci Eng C 2007; 27: 262-266.

[138] Zeugolis DI, Khew ST, Yew ESY, et al. Electro-spinning of pure collagen nano-fibres Just an expensive way to make gelatin? Biomaterials 2008; 29: 2293-2305.

[139] Szentivanyi A, Assmann U, Schuster R, et al. Production of biohybrid protein/PEO scaffolds by electrospinning. Mater Werkst 2009; 40: 65-72.

[140] Buttafoco L, Kolkman NG, EngbersBuijtenhuijs $\mathrm{P}$, et al. Electrospinning of collagen and elastin for tissue engineering applications. Biomaterials 2006; 27: 724-734.
[141] Elamparithi A, Punnoose AM, Kuruvilla S. Electrospun type 1 collagen matrices preserving native ultrastructure using benign binary solvent for cardiac tissue engineering. Artif Cells Nanomedicine Biotechnol 2016; 44: 1318-1325.

[142] Xu Y, Wu J, Wang $\mathrm{H}$, et al. Fabrication of Electrospun Poly(L-Lactide-co- $\varepsilon$ Caprolactone)/Collagen Nanoyarn Network as a Novel, Three-Dimensional, Macroporous, Aligned Scaffold for Tendon Tissue Engineering. Tissue Eng Part C Methods 2013; 19: pp. 925-936.

[143] Deville S. Ice-templating, freeze casting: Beyond materials processing. J Mater Res 2013; 28: 2202-2219.

[144] Haugh MG, Murphy CM, O'Brien FJ. Novel freeze-drying methods to produce a range of collagen-glycosaminoglycan scaffolds with tailored mean pore sizes. Tissue Eng Part C Methods 2009; 16: 887-894.

[145] Pawelec KM, Husmann A, Best SM, et al. A design protocol for tailoring ice-templated scaffold structure. J R Soc Interface 2014; 11: 1.

[146] Pawelec KM, Husmann A, Best SM, et al. Understanding anisotropy and architecture in ice-templated biopolymer scaffolds. Mater Sci Eng C 2014; 37: 141-147.

[147] Pawelec KM, Husmann A, Wardale RJ, et al. Ionic solutes impact collagen scaffold bioactivity. J Mater Sci Mater Med 2015; 26: 91.

[148] Pawelec KM, Husmann A, Best SM, et al. Altering crystal growth and annealing in icetemplated scaffolds. J Mater Sci 2015; 50: 7537-7543.

[149] Pawelec KM, Wardale RJ, Best SM, et al. The effects of scaffold architecture and fibrin gel addition on tendon cell phenotype. J Mater Sci Mater Med 2015; 5349.

[150] Davidenko N, Bax DV, Schuster CF et al. Optimisation of UV irradiation as a binding site conserving method for crosslinking collagen-based scaffolds. J Mater Sci Mater Med 2016; 27: 14.

[151] Lowe CJ, Reucroft IM, Grota MC, et al. Production of Highly Aligned Collagen Scaffolds by Freeze-drying of Self-assembled, Fibrillar Collagen Gels. ACS Biomater Sci Eng 2016; 2: 643-651.

[152] Caliari SR, Harley BAC. The effect of anisotropic collagen-GAG scaffolds and growth factor supplementation on tendon cell 
recruitment, alignment, and metabolic activity. Biomaterials 2011; 32: 5330-5340.

[153] Caliari SR, Harley BAC. Composite Growth Factor Supplementation Strategies to Enhance Tenocyte Bioactivity in Aligned CollagenGAG Scaffolds. Tissue Eng Part A 2013; 19: $1100-1112$.

[154] Caliari SR, Ramirez MA, Harley BAC. The development of collagen-GAG scaffoldmembrane composites for tendon tissue engineering. Biomaterials 2011; 32: 89908998.

[155] Caliari SR, Weisgerber DW, Grier WK, et al. Collagen Scaffolds Incorporating Coincident Gradations of Instructive Structural and Biochemical Cues for Osteotendinous Junction Engineering. Adv Healthc Mater 2015; 4: 831837.

[156] Mozdzen LC, Rodgers R, Banks JM, et al. Increasing the strength and bioactivity of collagen scaffolds using customizable arrays of 3D-printed polymer fibers. Acta Biomater 2016; 33: 25-33.

[157] McCullough EJ, Yadavalli VK. Surface modification of fused deposition modeling ABS to enable rapid prototyping of biomedical microdevices. J Mater Process Technol 2013; 213: 947-954.

[158] Murphy SV, AtalaA. 3D bioprinting of tissues and organs. Nat Biotechnol 2014; 32: 773785.

[159] Derby B. Printing and Prototyping of Tissues and Scaffolds. Science 2012; 338: 921-926.

[160] Do A-V, Khorsand B, Geary SM, et al. 3D Printing of Scaffolds for Tissue Regeneration Applications. Adv Healthc Mater 2015; 4: 1742-1762.

[161] Inzana JA, Olvera D, Fuller SM, et al. 3D printing of composite calcium phosphate and collagen scaffolds for bone regeneration. Biomaterials 2014; 35: 4026-4034.

[162] Duarte Campos DF, Blaeser A, Buellesbach K, et al. Bioprinting Organotypic Hydrogels with Improved Mesenchymal Stem Cell Remodeling and Mineralization Properties for Bone Tissue Engineering. Adv Healthc Mater 2016; 5: 1336-1345.

[163] Lin K-F, He S, Song Y, et al. LowTemperature Additive Manufacturing of Biomimic Three-Dimensional Hydroxyapatite/Collagen Scaffolds for Bone Regeneration. ACS Appl Mater Interfaces, 2016; 8: 6905-6916.

[164] Park JY, Choi J-C, Shim J-H, et al. A comparative study on collagen type I and hyaluronic acid dependent cell behavior for osteochondral tissue bioprinting. Biofabrication 2014; 6: 035004.

[165] Legemate $\mathrm{K}$, Tarafder S, Jun $\mathrm{Y}$, et al. Engineering Human TMJ Discs with ProteinReleasing 3D-Printed Scaffolds. J Dent Res 2016; 95: 800-807.

[166] Lee HJ, Kim YB, Ahn SH, et al. A New Approach for Fabricating Collagen/ECMBased Bioinks Using Preosteoblasts and Human Adipose Stem Cells. Adv Healthc Mater 2015; 4: 1359-1368.

[167] Wu Z, Su X, Xu Y, et al. Bioprinting threedimensional cell-laden tissue constructs with controllable degradation. Sci Rep 2016; 6: 24474.

[168] Xu T, Binder KW, Albanna M, et al. Hybrid printing of mechanically and biologically improved constructs for cartilage tissue engineering applications. Biofabrication 2013; 5: 015001 .

[169] Sun K, Li R, Jiang W, et al. Comparison of three-dimensional printing and vacuum freezedried techniques for fabricating composite scaffolds. Biochem Biophys Res Commun 2016; 477: 1085-1091.

[170] Lode A, Meyer M, Brüggemeier S, et al. Additive manufacturing of collagen scaffolds by three-dimensional plotting of highly viscous dispersions. Biofabrication 2016; 8: 015015.

[171] Liu CZ, Xia ZD, Han ZW, et al. Novel 3D collagen scaffolds fabricated by indirect printing technique for tissue engineering. J Biomed Mater Res B Appl Biomater 2008; 85: 519-528.

[172] Ahn S, Lee S, Cho Y, et al. Fabrication of three-dimensional collagen scaffold using an inverse mould-leaching process. Bioprocess Biosyst Eng 2011; 34: 903-911.

[173] Yeo M, Lee J-S, Chun W, et al. An Innovative Collagen-Based Cell-Printing Method for Obtaining Human Adipose Stem Cell-Laden Structures Consisting of Core-Sheath Structures for Tissue Engineering. Biomacromolecules 2016; 17: 1365-1375.

[174] Moon S, Hasan SK, Song YS, et al. Layer by layer three-dimensional tissue epitaxy by cellladen hydrogel droplets. Tissue Eng Part C Methods 2009; 16: 157-166.

[175] Kang H-W, Lee SJ, Ko IK, et al. A 3D bioprinting system to produce human-scale tissue constructs with structural integrity. Nat Biotechnol 2016; 34: 312-319.

[176] Merceron TK, Burt M, Seol Y-J, et al. A 3D bioprinted complex structure for engineering 
the muscle-tendon unit. Biofabrication 2015; 7: 035003.

[177] Baker HR, Merschrod S EF, Poduska KM. Electrochemically Controlled Growth and Positioning of Suspended Collagen Membranes. Langmuir 2008; 24: 2970-2972.

[178] Cheng X, Gurkan UA, Dehen CJ, et al. An electrochemical fabrication process for the assembly of anisotropically oriented collagen bundles. Biomaterials 2008; 29: 3278-3288.

[179] Younesi M, Islam A, Kishore V, et al. Fabrication of compositionally and topographically complex robust tissue forms by 3D-electrochemical compaction of collagen. Biofabrication 2015; 7: 035001.

[180] Abu-Rub MT, Billiar KL, van Es MH, et al. Nano-textured self-assembled aligned collagen hydrogels promote directional neurite guidance and overcome inhibition by myelin associated glycoprotein. Soft Matter 2011; 7: 2770- 2781.

[181] Uquillas JA, Kishore V, Akkus O, Effects of phosphate-buffered saline concentration and incubation time on the mechanical and structural properties of electrochemically aligned collagen threads. Biomed Mater 2011; 6: 035008.

[182] Kishore V, Bullock W, Sun X, et al. Tenogenic differentiation of human MSCs induced by the topography of electrochemically aligned collagen threads. Biomaterials 2012; 33:2137-2144.

[183] Kishore V, Uquillas JA, Dubikovsky A, et al. In vivo response to electrochemically aligned collagen bioscaffolds. J Biomed Mater Res B 2012; 100B: 400-408.

[184] Uquillas JA, Kishore V, Akkus O. Genipin crosslinking elevates the strength of electrochemically aligned collagen to the level of tendons. J Mech Behav Biomed Mater 2012; 15:176-189.

[185] Younesi M, Islam A, Kishore $\mathrm{V}$, et al. Tenogenic Induction of Human MSCs by Anisotropically Aligned Collagen Biotextiles. Adv Funct Mater 2014; 24: 5762-5770.

[186] Islam A, Chapin $\mathrm{K}$, Younesi $\mathrm{M}$, et al. Computer aided biomanufacturing of mechanically robust pure collagen meshes with controlled macroporosity. Biofabrication 2015; 7: 035005.

[187] Bell E, Ivarsson B, Merrill C. Production of a tissue-like structure by contraction of collagen lattices by human fibroblasts of different proliferative potential in vitro. Proc Natl Acad Sci 1979: 76: 1274-1278.
[188] Stopak D, Harris AK. Connective tissue morphogenesis by fibroblast traction: I. Tissue culture observations. Dev Biol 1982; 90: 383398.

[189] Barocas VH, Tranquillo RT. An anisotropic biphasic theory of tissue-equivalent mechanics: the interplay among cell traction, fibrillar network deformation, fibril alignment, and cell contact guidance. J Biomech Eng 1997; 119: 137-145.

[190] Huang D, Chang TR, Aggarwal A, et al. Mechanisms and dynamics of mechanical strengthening in ligament-equivalent fibroblast-populated collagen matrices. Ann Biomed Eng 1993; 21: 289-305.

[191] Young RG, Butler DL, Weber W, et al. Use of mesenchymal stem cells in a collagen matrix for Achilles tendon repair. J Orthop Res 1998; 16: 406-413.

[192] Awad HA, Boivin GP, Dressler MR, et al. Repair of patellar tendon injuries using a cellcollagen composite. J Orthop Res 2003; 21: 420-431.

[193] Butler DL, Juncosa-Melvin N, Boivin GP, et al. Functional tissue engineering for tendon repair: A multidisciplinary strategy using mesenchymal stem cells, bioscaffolds, and mechanical stimulation. J Orthop Res 2008; 26: 1-9.

[194] Juncosa-Melvin N, Boivin GP, Galloway MT, et al. Effects of cell-to-collagen ratio in mesenchymal stem cell-seeded implants on tendon repair biomechanics and histology. Tissue Eng 2005; 1: 448-457.

[195] Calve S, Dennis RG, Kosnik PE, et al. Engineering of functional tendon. Tissue Eng 2004; 10: 755-761.

[196] Swasdison S, Mayne R. Formation of highly organized skeletal muscle fibers in vitro. Comparison with muscle development in vivo. J Cell Sci 1992; 102: 643-652:

[197] Larkin LM, Calve S, Kostrominova TY, et al. Structure and Functional Evaluation of Tendon-Skeletal Muscle Constructs Engineered in Vitro. Tissue Eng 2006; 12: 3149-3158.

[198] Kapacee Z, Richardson SH, Lu Y, et al., Tension is required for fibripositor formation. Matrix Biol 2008; 27: 371-375.

[199] Guerquin M-J, Charvet B, et al., Nourissat G, et al. Transcription factor EGR1 directs tendon differentiation and promotes tendon repair. $\mathbf{J}$ Clin Invest 2013; 123: 3564-3576.

[200] Neal D, Sakar MS, Ong L-LS, et al. Formation of elongated fascicle-inspired 3D tissues 
consisting of high-density, aligned cells using sacrificial outer molding. Lab Chip 2014; 14: 1907.

[201] Yeung C-YC, Zeef LAH, Lallyett C, et al. Chick tendon fibroblast transcriptome and shape depend on whether the cell has made its own collagen matrix. Sci Rep 2015; 5: 13555.

[202] Breidenbach AP, Dyment NA, Lu Y, et al. Fibrin Gels Exhibit Improved Biological, Structural, and Mechanical Properties Compared with Collagen Gels in Cell-Based Tendon Tissue-Engineered Constructs. Tissue Eng Part A 2015; 21: 438-450.

[203] Torbet J, Ronziere M-C. Magnetic alignment of collagen during self-assembly. Biochem $\mathrm{J}$ 1984; 219: 1057-1059.

[204] Guido S, Tranquillo RT. A methodology for the systematic and quantitative study of cell contact guidance in oriented collagen gels. Correlation of fibroblast orientation and gel birefringence. J Cell Sci 1993; 105: 317-331.

[205] Chen S, Hirota N, Okuda M, et al. Microstructures and rheological properties of tilapia fish-scale collagen hydrogels with aligned fibrils fabricated under magnetic fields. Acta Biomater 2011. 7: 644-652.

[206] Guo C, Kaufman LJ. Flow and magnetic field induced collagen alignment. Biomaterials 2007; 28: 1105-1114.

[207] Lee P, Lin R, Moon J, et al. Microfluidic alignment of collagen fibers for in vitro cell culture. Biomed Microdevices 2006; 8: 35-41.

[208] Saeidi N, Sander EA, Ruberti JW. Dynamic shear-influenced collagen self-assembly. Biomaterials 2009; 30: 6581-6592.

[209] Lanfer B, Freudenberg U, Zimmermann R, et al. Aligned fibrillar collagen matrices obtained by shear flow deposition. Biomaterials 2008; 29: 3888-3895.

[210] Haynl C, Hofmann E, Pawar K, et al. Microfluidics-Produced Collagen Fibers Show Extraordinary Mechanical Properties. Nano Lett 2016; 16: 5917-5922.

[211] Yunoki S, Hatayama H, Ebisawa M, et al. A novel fabrication method to create a thick collagen bundle composed of uniaxially aligned fibrils: An essential technology for the development of artificial tendon/ligament matrices. J Biomed Mater Res A 2015; 103: 3054-3065.

[212] Paten JA, Siadat SM, Susilo ME, et al. FlowInduced Crystallization of Collagen: A Potentially Critical Mechanism in Early Tissue Formation. ACS Nano 2016; 10: 5027-5040.
[213] Brown RA, Wiseman M, Chuo C-B, et al. Ultrarapid Engineering of Biomimetic Materials and Tissues: Fabrication of Nanoand Microstructures by Plastic Compression. Adv Funct Mater 2005; 15: 1762-1770.

[214] Ghezzi CE, Muja N, Marelli B, et al. Real time responses of fibroblasts to plastically compressed fibrillar collagen hydrogels. Biomaterials 2011; 32: 4761-4772.

[215] Mudera V, Morgan M, Cheema U, et al. Ultrarapid engineered collagen constructs tested in anin vivo nursery site. J Tissue Eng Regen Med 2007; 1: 192-198.

[216] Marelli B, Ghezzi CE, James-Bhasin M, et al. Fabrication of injectable, cellular, anisotropic collagen tissue equivalents with modular fibrillar densities. Biomaterials 2015; 37:183193.

[217] Killian ML, Cavinatto L, Galatz LM, et al. The role of mechanobiology in tendon healing. $\mathrm{J}$ Shoulder Elbow Surg 2012; 21: 228-237.

[218] Pins GD, Huang EK, Christiansen DL, et al. Effect of static axial strain on the tensile properties and failure mechanisms of selfassembled collagen fibers. J Appl Polym Sci 1997; 63: 1429-1440.

[219] Chaubaroux C, Perrin-Schmitt F, Senger B, et al. Cell Alignment Driven by Mechanically Induced Collagen Fiber Alignment in Collagen/Alginate Coatings. Tissue Eng Part C Methods 2015; 21: 881-888.

[220] Cheema U, Chuo C-B, Sarathchandra P, et al. Engineering Functional Collagen Scaffolds: Cyclical Loading Increases Material Strength and Fibril Aggregation. Adv Funct Mater 2007; 17: 2426-2431.

[221] Zeichen J, van Griensven M, Bosch U. The proliferative response of isolated human tendon fibroblasts to cyclic biaxial mechanical strain. Am J Sports Med 2000; 28: 888-892.

[222] Riboh J, Chong AKS, Pham H, et al. Optimization of Flexor Tendon Tissue Engineering With a Cyclic Strain Bioreactor. J Hand Surg 2008; 33: 1388-1396.

[223] Zhang L, Kahn CJF, Chen H-Q, et al. Effect of uniaxial stretching on rat bone mesenchymal stem cell: Orientation and expressions of collagen types I and III and tenascin-C. Cell Biol Int 2008; 32: 344-352.

[224] Garvin J, Qi J, Maloney M, et al. Novel system for engineering bioartificial tendons and application of mechanical load. Tissue Eng 2003; 9: 967-979. 
[225] Kuo CK, Tuan RS. Mechanoactive Tenogenic Differentiation of Human Mesenchymal Stem Cells. Tissue Eng Part A 2008; 14: 1615-1627.

[226] Scott A, Danielson P, Abraham T, et al. Mechanical force modulates scleraxis expression in bioartificial tendons. $\mathrm{J}$ Musculoskelet Neuronal Interact 2011; 11: 124-132.

[227] Juncosa-Melvin N, Shearn JT, Boivin GP et al. Effects of mechanical stimulation on the biomechanics and histology of stem cellcollagen sponge constructs for rabbit patellar tendon repair. Tissue Eng 2006; 12: 22912300.

[228] Juncosa-Melvin N, Matlin KS, Holdcraft RW, et al. Mechanical Stimulation Increases Collagen Type I and Collagen Type III Gene Expression of Stem Cell-Collagen Sponge Constructs for Patellar Tendon Repair. Tissue Eng 2007; 13: 1219-1226.

[229] Nirmalanandhan VS, Shearn JT, JuncosaMelvin $\mathrm{N}$ et al. Improving Linear Stiffness of the Cell-Seeded Collagen Sponge Constructs by Varying the Components of the Mechanical Stimulus. Tissue Eng. Part A 2008; 14: 18831891.

[230] Shearn JT, Juncosa-Melvin N, Boivin GP et al. Mechanical Stimulation of Tendon Tissue Engineered Constructs: Effects on Construct Stiffness, Repair Biomechanics, and Their Correlation. J Biomech Eng 2007; 129: 848854.

Received: $\quad$ Revised:

